\title{
Development of an amplified added stiffening and damping system for wood-frame shear walls.
}

\author{
Jairo Montaño ${ }^{a, b *}$ (D), Rudy Maurya (D), José Luis Almazán ${ }^{a}$ (D) , Xavier Estrella ${ }^{a, b, c}$ (D), Pablo Guindos ${ }^{a, b}$ (iD) \\ a Pontificia Universidad Católica de Chile, Av. Vicuña Mackenna, Santiago 7820436, Chile. E-mail: jamontano@uc.cl, r.maury@uc.cl, \\ jlalmaza@ing.puc.cl, exestrella@uc.cl,pguindos@ing.puc.cl \\ b UC Timber Innovation Center, Av. Vicuña Mackenna, Santiago 7820436, Chile. \\ c University of Technology Sydney, 81 Broadway Street, Ultimo NSW 2007, Australia. \\ *Corresponding author
}

http://dx.doi.org/10.1590/1679-78256109

\begin{abstract}
The effectiveness of seismic dampers to improve the lateral performance of timber structures may be heavily diminished if restrictive lateral drift limits as set by building codes, governs the design of the structure. This paper presents an innovative approach to improve the performance of seismic dampers installed in stiff wood-frame shear walls. U-Shape Flexural Plate dampers with a novel internal restraint system, were installed in a $4880 \times 2475 \mathrm{~mm}$ wood-frame shear wall with an Eccentric Lever-Arm System which aimed at amplifying the displacements by transferring them from the shear wall to the dampers. Cyclic tests were conducted to four specimens. Initial test results showed that the presented amplifying system suffered concentrated losses of stiffness at some connections joints reducing its real efficiency. The loss of displacement transmission to dampers was retrofitted, and the results showed a great benefit in terms of resilience for the damped shear wall in contrast with unprotected ones. It was found that this approach provides a feasible solution to enhance the lateral performance of wood-frame structures.
\end{abstract}

\section{Keywords}

Wood, timber, shear wall, damper, seismic performance, lateral resistance, resilience.

\section{Graphical Abstract}
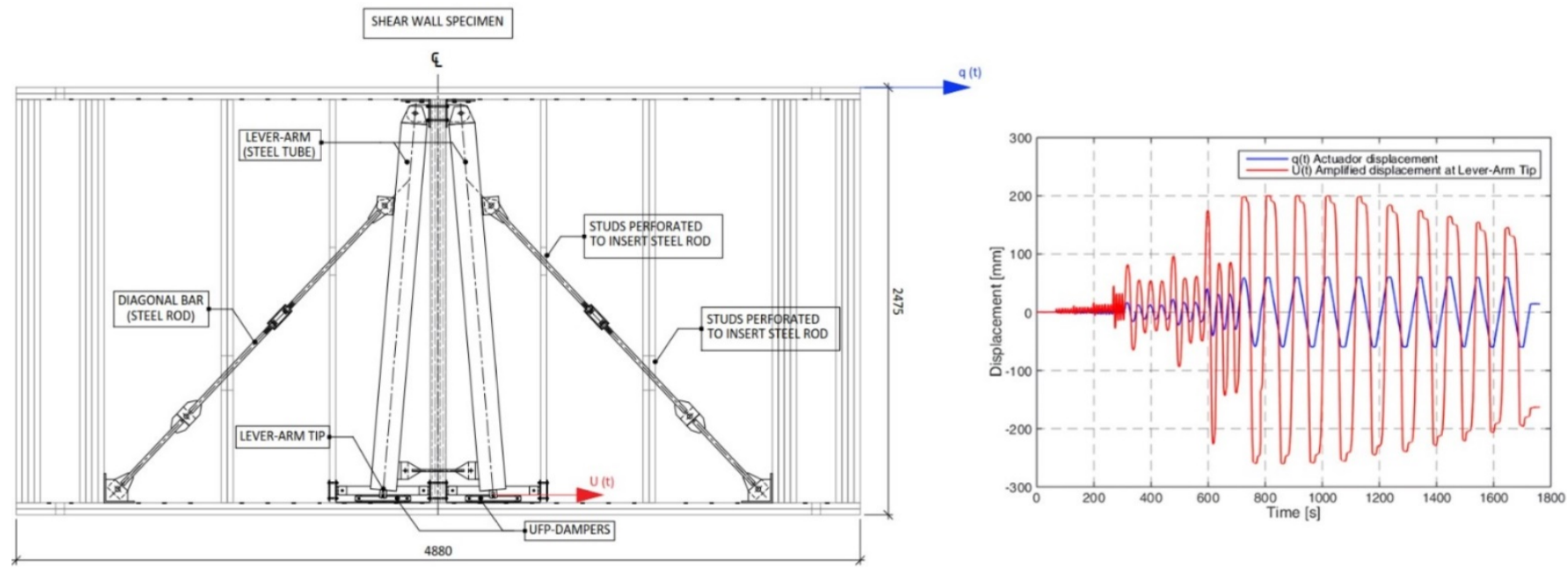


\section{INTRODUCTION}

Supplemental energy dissipation systems have gained ground in the last two decades among wood-frame structures since these seismic protection systems allow reducing the structural response under lateral loads by providing additional means to absorb the kinetic energy induced by earthquakes. Therefore, this paper presents a discussion about the use and application of seismic dissipation devices coupled to displacement amplification systems for wood-frame shear walls, where the amplification system is an interesting mechanism added up to the shear wall in order to improve the performance of the damper. The concept of such mechanism is explained in detail in the subsequent sections. Hence, the main goal of this study is to experimentally evaluate the behavior of the: wall-amplifier-damper system, highlighting the experiences obtained during the learning process to adapt the displacement amplifier mechanism and the seismic dissipation devices into the specimen shear wall.

The wood-frame system has a constant and significant presence in the construction market for mid-rise timber buildings (up to 6 stories) in many countries. This is because this system has the best cost-effectiveness ratio up to that number of stories, as well as other benefits related to prefabrication, low carbon footprint, and high thermal isolation, among others. Although there are other Lateral Force Resisting Systems (LFRS) availables for the construction of timber buildings (such as mass timber shear walls, glued laminated timber, braced beam-column systems, among others), these generally make economic sense for buildings construction over 7 stories high, especially in earthquake-prone areas.

However, regardless of the LFRS used for timber buildings, the main problem that controls the technical feasibility of their structural designs under lateral loads, and their subsequent economic feasibility when are located at high seismic zones, is the lateral flexibility of these wooden structural systems. The issues regarding this technical feasibility come up when trying to meet the lateral stiffness requirements prescribed by the seismic design code, which in Chile govern all construction materials equally. Therefore, due to the inherent lateral flexibility of timber structures, they have greater complications to achieve the high lateral stiffnesses required to control the interstory drifts, thus being at a disadvantage when compared to other materials. On the other hand, considering that the conventional seismic design approach (without seismic protection systems) solves the low stiffness of the LFRS by oversizing certain structural elements, they ended up being expensive structural solutions for timber buildings hindering this way their economic feasibility.

Additionally, since this conventional design approach does not take into account additional sources of damping other than the intrinsic of the structural system, it dissipates all seismic energy through inelastic deformations, expecting controlled damage to the structure but without quantifying this potential damage at the non-structural elements. All these issues disadvantage timber construction systems compared to other stiffer systems used in Chile. In this way, the lack of stiffness finally results in cost overruns, while the lack of damping leads to uncertainties regarding potential damage to non-structural elements.

Some authors assumed that wood-frame walls dissipate much energy through the framing-to-sheathing connection. Therefore, no additional energy dissipation systems are considered necessary (Ugalde et al. 2019). However, this idealized high energy dissipation is not real because of the pinching effect. It has been experimentally observed that wood-frame shear walls dissipate considerable energy in the first cycle of lateral displacement, but in the following displacement cycles, the same trend is not observed. Further energy dissipation in the following cycles comes from nails that did not fail at previous cycles, or from same nails when they are brought to higher levels of deformation and come into contact with the crushed wood from the previous cycle. Therefore, if the energy dissipated per cycle is evaluated considering the pinching effect instead of the energy dissipated by the monotonic envelope, plunges of about $90 \%$ are observed for the dissipation levels. Evidencing thus that the high energy dissipation of wood-frame shear walls is not realistic and justifies the need to include dissipation systems to the structure.

Another concept that supports the need for adding extra dissipation systems to wood-frame shear walls is the drift level at which the inelastic behavior begins. It has been experimentally observed that stiffness degradation occurs at very early stages of lateral deformation. Therefore, seismic dissipation systems are also justified to avoid harmful residual deformations at low levels of lateral displacement.

As mentioned above, the conventional seismic design approach needs to include very stiff shear walls due to the drift limits set by building codes. According to previous investigations, this causes that the walls do not generate enough relative displacement to activate the dissipation systems. For instance, Symans and Constantinou (1998) found that installing dissipation systems on flexible structures is more efficient compared to their applications on rigid structures, due to the low deformations that rigid structures transferred to the dissipators. Therefore, this leads to the need to employ certain mechanisms that amplify the low amplitude deformations induced by lateral movements of rigid structures. This concept involves installing the so-called Amplification Mechanisms (AM) at the shear wall, and then connecting the dampers to these AMs, which have a geometry such that during lateral deformations the relative displacements of the wall are amplified and transferred directly to the dissipator, generating in the latter enough 
deformation to guarantee that it provides an adequate level of damping to the shear wall. This combination of an AM with one or more dampers is generically called Amplified Added Damping (AAD). On the other hand, if the AM also adds stiffness to the shear wall, the system is called Amplified Added Stiffening and Damping (AASD).

As a result of the above discussion, this research project aims at seeking solutions that allow improving the lateral performance of wood-frame shear walls for 5 to 6 story timber buildings. This research starts at how to integrate and adapt low-cost U-Shape Flexural Plate (UFP) energy dissipators along with a double Eccentric Lever-Arm System (ELAS) amplification system to a wood-frame shear wall. The integration of the AASD system with the wood-frame shear wall is experimentally evaluated through reversed cyclic tests that allow studying its effectiveness, understanding its seismic behavior, and developing an experimental database for future numerical models. Subsequently, the performance of the AASD system applied on a multiple-degrees-of-freedom shear wall is evaluated through a linear response-history analysis. This aims at verifying the contribution level of the AASD system to reduce the interstory drifts as required by the seismic design code for buildings in Chile.

\section{ENERGY DISSIPATION IN WOOD-FRAME SHEAR WALLS AND THE RELEVANCE OF DISPLACEMENT AMPLIFICATION MECHANISMS}

This section provides a background overview of the use of energy dissipators in wood-frame shear walls. This aims at introducing the disadvantages of their application in rigid structures, to subsequently highlight the relevance of using displacement amplification mechanisms to improve the performance of the dampers within the shear wall. Then, certain aspects of the state-of-the-art of the AMs are briefly described, as well as the main characteristics on which its efficiency once installed at the structure depends on.

\subsection{Brief literature review of seismic protection systems with energy dissipators for wood-frame shear walls.}

In order to incorporate additional energy dissipation to protect wood-frame structures from earthquakes, previous researchers have tested frictional and elastoplastic dampers as a means to provide complementary damping, reporting different levels of success. The use of dampers seems to be a good solution for timber structures since they can be easily attached and replaced, offer the possibility of adding significant lateral stiffness to flexible systems, and also allow to increase the elastic limits of timber structures. This offers the possibility of fully harnessing the dissipative potential of seismic dampers. In this context, energy dampers have been tested on wood-frame shear walls under different configurations (Ugalde et al. 2019): Filiatrault (1990) and Li et al. (2017) tested walls with frictional dissipators, Dinehart et al. (1999) tested walls with viscoelastic dissipators, Higgins (2001) tested yield dissipators, and Symans et al. (2002a) and Dutil and Symans (2004) investigated viscous fluid dampers using typical diagonal and chevron configurations, as shown in Figure 1. 


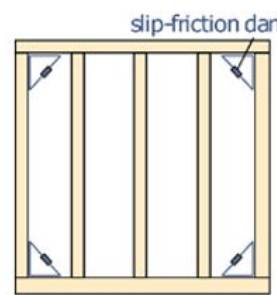

(a)

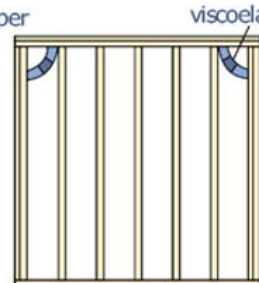

(b)

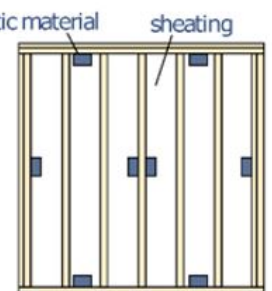

(c)

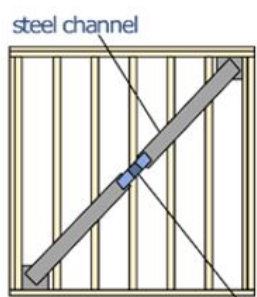

(d)

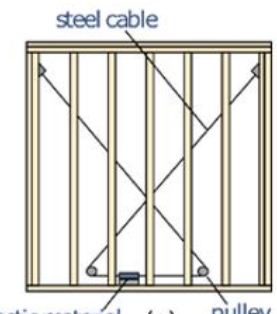

(e)

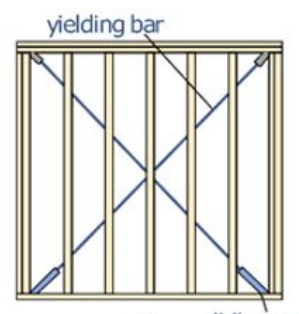

(f) sliding connection

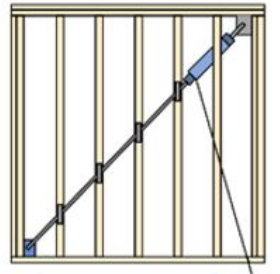

(g)

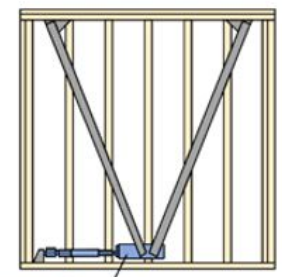

(h)

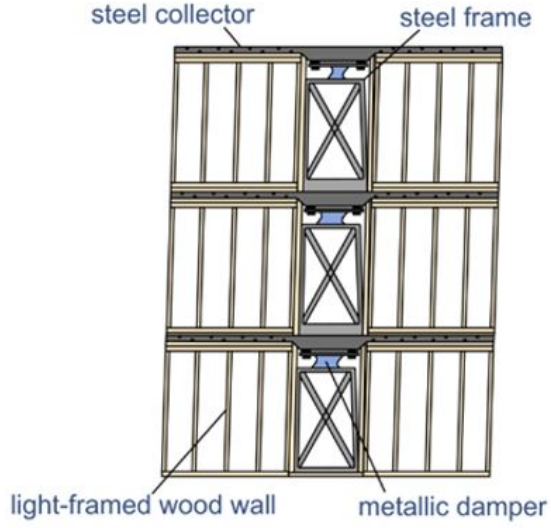

(i)

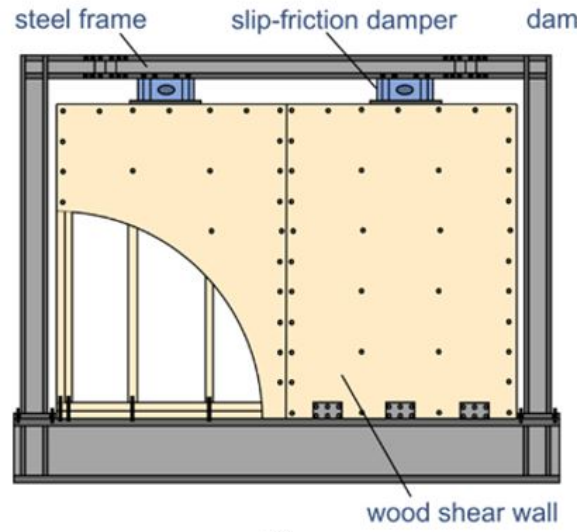

(j)

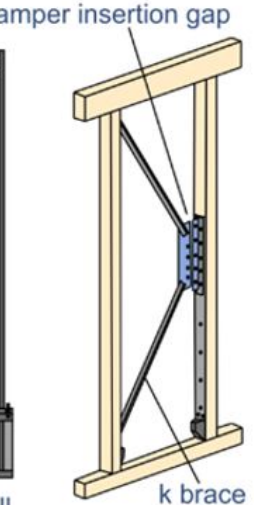

(k)

Figure 1. Different tested configurations of supplemental damping in wood-framed shear walls from Ugalde et al. 2019: (a) Filiatrault (1990), (b) to (e) Dinehart et al. (1999), (f) Higgins (2001), (g) Symans et al. (2002a), (h) Dutil and Symans (2004), (i) López-Almansa et al. (2015), (j) Li et al. (2017) and (k) Kasai et al. (2005).

However, all previous applications of energy dissipators in wood-frame shear walls are based on the straight transmission of displacements from the wall to the dissipator. In other words, they are dissipator applications without using AMs, which are generally appropriate only for use in flexible structures, according to Baquero et al. (2016).

During Phase 2 of the NEESWood benchmark testing program, the implementation of seismic damping systems to wood-frame structures was investigated experimentally through shake table tests, as reported by Shinde and Symans (2010). Two shear wall configurations were studied including viscous fluid dampers. The first shear wall configuration considered a straight transmission of the displacement from the wall to the dissipator via a chevron system. The second wall configuration considered dissipators with a toggle-braced AM. This resulted in an AAD system, as shown in Figure 2.

The tests showed significant losses (about $40 \%$ to $60 \%$ ) in the displacement transmission from the shear walls to the dissipators. This was due to the limited coupling of the dampers with the walls during the tests because of the inherent flexibility of the connections in timber structures. Therefore, the potential of the dissipators was not fully harnessed. However, a significant improvement in the performance was observed for the shear walls with the toggle-braced AM, a result also reported by Shinde et al. (2008). 


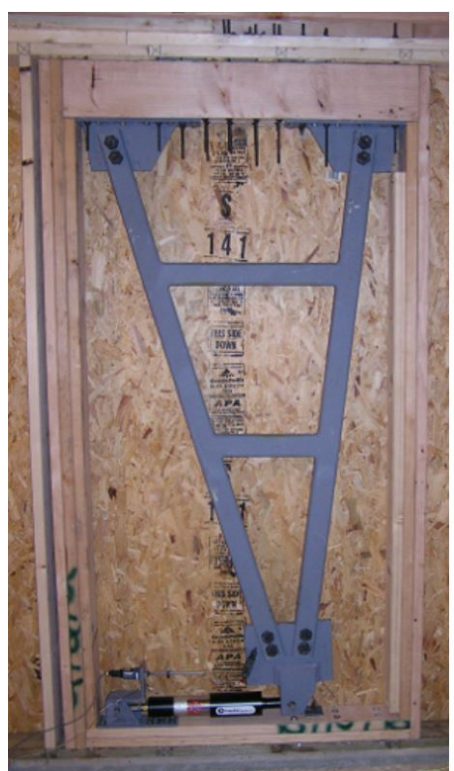

(a)

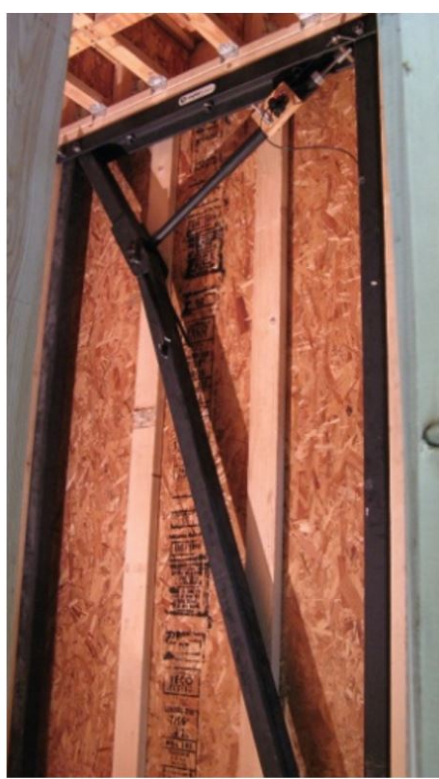

(b)

Figure 2. Wood-frame shear wall configurations with energy dissipators reported by Shinde and Symans (2010): (a) chevron-brace design, and (b) toggle-brace design.

\subsection{Brief literature review of amplification mechanisms and their efficiency characteristics.}

As noted by Shinde and Symans (2010), different displacement AM configurations have been proposed in the literature to address the problem related to the low amplitude displacements in rigid structures. Berton and Bolander (2005) developed a displacement amplification device employing pinion mechanisms. Taylor Devices Inc., proposed and patented the toggle-brace damping system in 1996 ("Toggle linkage seismic isolation structure", U.S. Patent Nos. 5870863 and 5934028, 1996). Figure 3 shows some of the most typical AMs that have been proposed by previous investigations: the scissor-jack system by Sigaher and Constantinou (2003), the toggle-brace system by Constantinou et al. (1997, 2001), and the lever-arm systems (LAS) by Kani et al. (1992). Similarly, there are other less used AMs such as the hydraulic-amplification devices proposed by Chung \& Lam (2004), the seesaw-damper system by Kang and Hiroshi (2012), Kang and Tagawa (2013, 2014), and the amplification systems based on pinions with different diameters by Berton and Bolander (2005).

As reported by Baquero et al. (2016), it is relevant to note that the efficiency of the AMs depends on the stiffness of the elements designed to transmit the lateral drift from the main structure to the energy dissipation devices. Because both the AM and the damper make up a single series system (an AAD or AASD system), only a portion of the lateral drift is transmitted to the dampers to dissipate energy, while the remaining is lost in the elastic deformations of the AM elements. Therefore, it is possible to define the efficiency of the AMs as the ratio of the total drift deformation (amplified or not) to move the damper to the actual deformation that the damper receives. Thus, the efficiency depends on the geometry and stiffness of the AM. The details of the AM proposed in this study are presented in section 3.2.

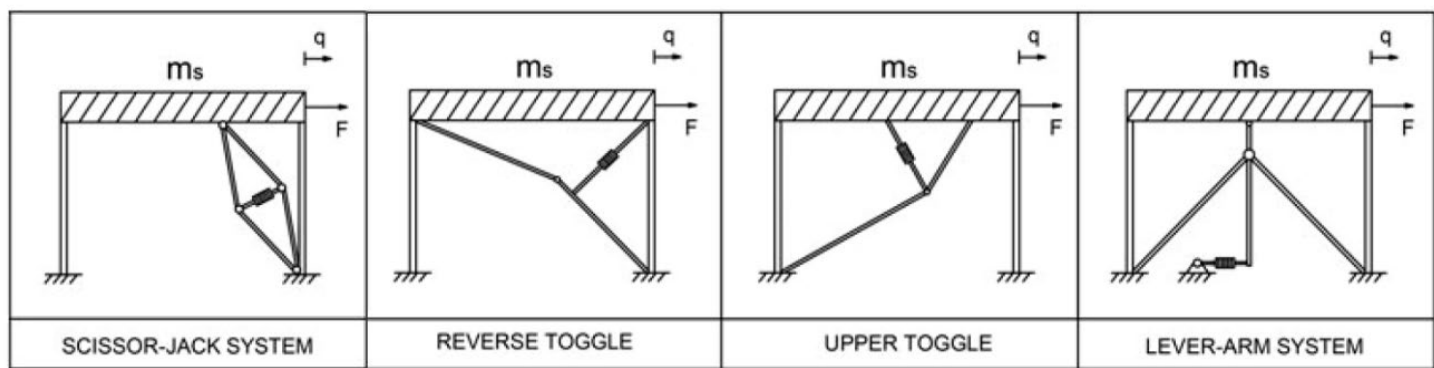

a)

b)

c)

d)

Figure 3. Schematic representation of some of the available amplification mechanisms (AM) from Baquero et al. (2016). 


\section{CRITERIA TO DEFINE THE CONFIGURATION AND DESIGN OF THE SHEAR WALL SPECIMEN}

This section examines the first research question regarding knowing and learning how to adapt a lateral displacement AM along with an energy dissipator within the structure of a typical wood-frame shear wall. As noted by Symans et al. (2002b), some of the challenges when using energy dissipation systems with wood-frame walls are:

- To install the dampers within the narrow limits of a wood-frame shear wall (typical width available is $139.7 \mathrm{~mm}$ [5.5 in] for nominal $2 \times 6$ in studs).

- To develop a suitable structural system for the dampers so that they can be integrated within the wood-frame wall and the lateral drift is transferred without major losses (the losses may be significant due to the intrinsic flexibility of the shear wall joints and connections of the wood-frame structure).

- To modify (if needed) the arrangement of the frame to install the dampers and assemble them.

The following paragraphs present a discussion of the criteria taken into account to choose the configurations of the wood-frame wall specimen and the energy dissipation system for this study.

\subsection{Selection of the shear wall typology for the test specimen: conventional shear wall}

This investigation was focused on improving the lateral behavior of wood-frame shear walls through seismic protection systems applied to 5 to 6 story buildings. Therefore, to define the specimen to be tested with the energy dissipation system, a typical shear wall of the first floor of a 6 -story building was taken as reference. A conventional shear wall with these characteristics is shown in Figure 4.

Figure 4 shows a wood-frame structure made for Anchor Tie-Down System (ATS) anchorages. The distinctive feature of these walls can be recognized in the end studs, as these are the vertical elements with the largest cross-section located at the ends of the wall, which are materialized through sets of several simple studs that are mechanically joined employing screws or nails to form a single structural element. Their primary function, in addition to taking gravitational loads, consists of resisting the compression forces generated by the overturning moments on the shear wall. In this shear wall configuration with ATS anchorages, the steel rods are the elements that resist the tensile loads, while the end studs only take the compression loads, which is one of the advantages of this type of anchorages since timber elements do not work well in tension.

The ATS anchorages consist of a steel rod installed inside the shear walls, which is continuous from the foundation to the top floor. This steel rod is placed at each corner of the shear wall to take the tensile forces and stiffen the structure when facing earthquake loads. Therefore, these anchoring systems are responsible for providing the wood-frame shear walls with the high lateral stiffnesses required by seismic design codes.

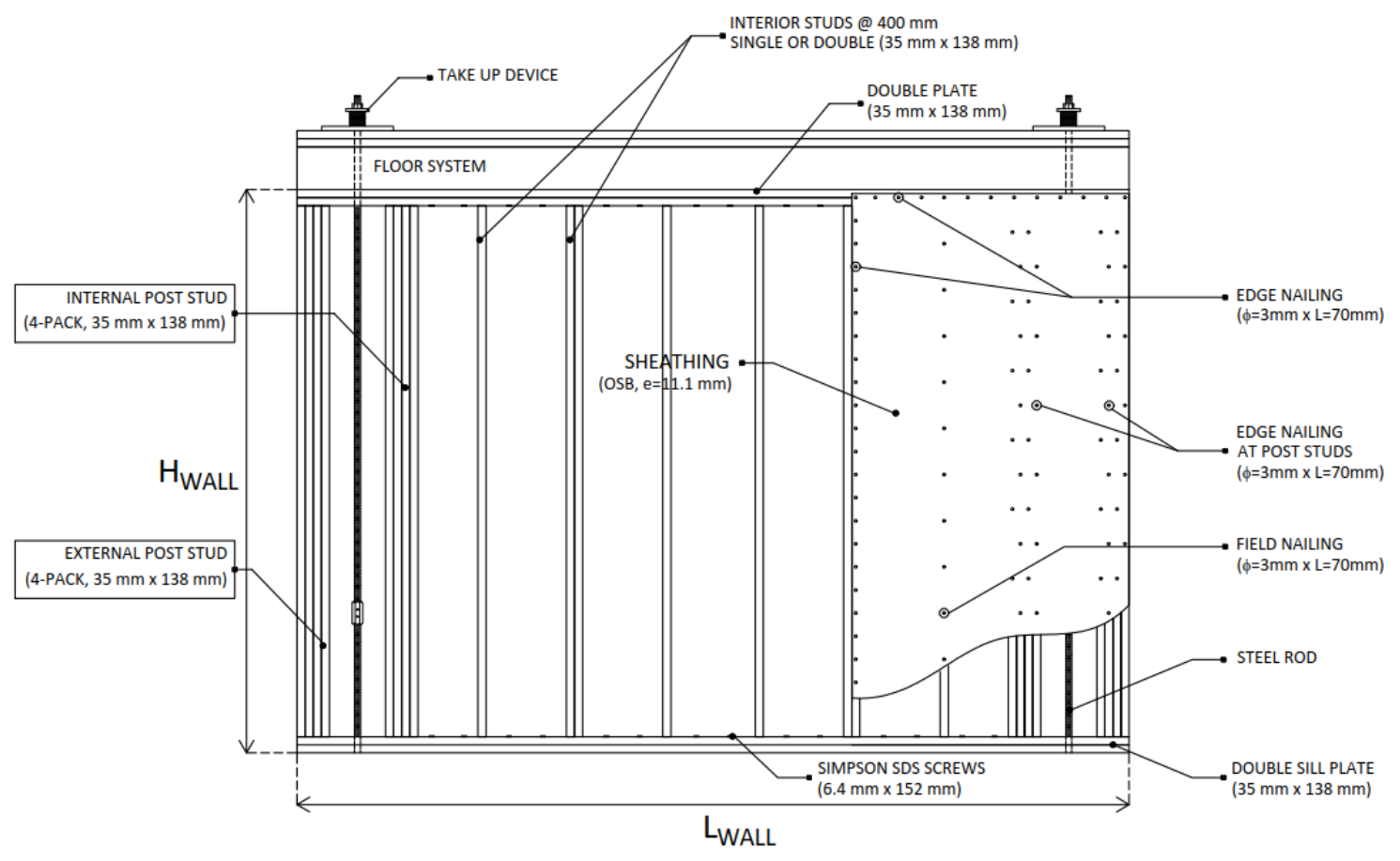

Figure 4. Conventional wood-frame shear wall designed for an anchorage type Anchor Tie-Down System. 
The problem with the implementation of ATS anchorages in wood-frame buildings is that these devices are an expensive solution. This is due to the structural design process that, when providing the shear walls with the stiffness required to control the lateral drift and to avoid overturning of the shear wall as a rigid body, results in oversizing the diameters of the steel rods, making this solution more expensive for all the components of the anchoring system. However, the resulting structural designs of wood-frame buildings of 5 to 6 stories in areas of high seismic intensity continue requiring their use, since the available commercial Hold-Down (HD) anchorages are not capable of providing the shear walls with the stiffness required to avoid overturning effects, neither are capable of resisting the high tensile forces generated. Therefore, this fact leaves the ATS anchorage system as the only solution available for mid-rise buildings. Consequently, this research project proposes to adapt energy dissipation systems and the AMs to walls with ATS anchorages, since they are the solution employed in buildings of 5 and 6 stories in areas of high seismic intensity. However, it should be noted that the anchors (ATS or HD) are precisely the components of the shear wall that result in very oversized designs, situation that hinders the economic feasibility of mid-rise buildings. Therefore, it is still necessary to advance in solutions that improve the lateral performance of wood-frame shear walls and reduce their costs.

Therefore, the challenge was focused on adapting and incorporating the displacement AM and the energy dissipator within the shear wall configuration shown in Figure 4. This implied fitting within the relatively narrow width of the timber frame and the gaps between the studs: i) the AM with its connections, ii) the connection of the AM with the damper, and iii) the connection of the damper to the timber frame. All the above seeking to modify the arrangement of the shear wall studs with the least negative impact on the shaer wall capacity under vertical loads.

\subsection{Selection of the amplification mechanism (AM) of displacement for the test specimen: Eccentric Lever-Arm System (ELAS)}

According to Baquero et al. (2016), the proposed AM is a variant of the well-known LAS mechanism developed by Kani et al. (1992) indicated in Figure 3(d) in Section 2.2. Figure 5(a) shows a typical configuration of the Eccentric Lever-Arm System (ELAS), which consists of a diagonal bar and a lever arm to which the damper is connected. There are two main differences between the ELAS and LAS: (i) in the LAS mechanism, the lever arm is symmetrically located in the center of the frame with one end connected to the midpoint of the top plate, while the ELAS has the lever arm connected to one upper corner of the frame (hence the name "eccentric") and is directly connected to the plate-end stud joint; and (ii) while the LAS mechanism is installed coupled to a secondary chevron system, the ELAS is coupled to a single diagonal bar.

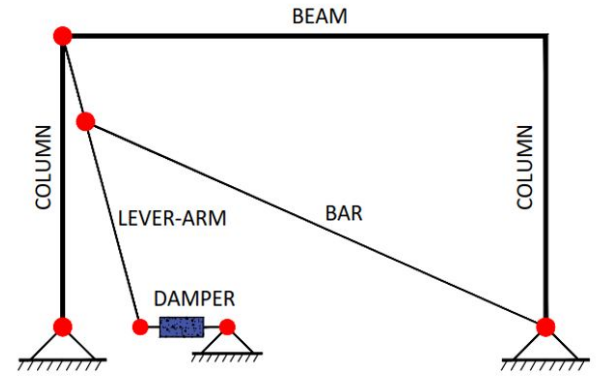

(a)

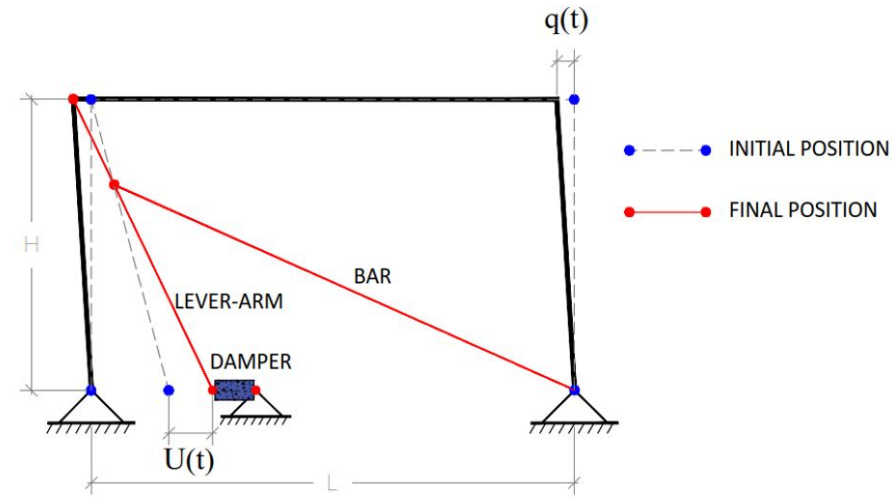

(b)

Figure 5. Eccentric Lever-Arm System (ELAS): (a) one damper (concentrated energy dissipation); and (b) deformed position.

Figure 5 shows that this AM only works when the diagonal bar is in tension, i.e., as long as the bar does not have a previous pretension load this AM will only work in the deformed direction shown in Figure 5(b), since in the other direction the bar will work in compression, easily buckling and losing the functionality of the lever. Although Baquero et al. (2016) proposed an efficient AM system that does work in both directions, for the purposes of this research, it is only of interest to highlight the basic operation principle of the ELAS in one direction, which will allow understanding its application in the test specimen of this study and the need to add two additional concepts (tie bar and pretension load) to make it work in both directions regardless if the bar is in tension or not.

Figure 6 shows the adapted shear wall configuration combining the concepts of the specimen in Figure 4 and the ELAS mechanism in Figure 5(a). A detailed view of the ELAS system is presented in Figure 7. Additional details and dimensions of the different elements are provided in Section 4.1. As observed from Figures 6 and 7, it can be noted that 
when adapting the ELAS into the shear wall, two ELAS mechanisms are needed (one on each side of the center of the wall). Therefore, two dampers can be installed within one shear wall, one with each ELAS mechanism. Different types of dampers (such as frictional, viscoelastic, or metallic) can be used with this AM. In this study, a metallic damper was chosen as explained in section 3.3.

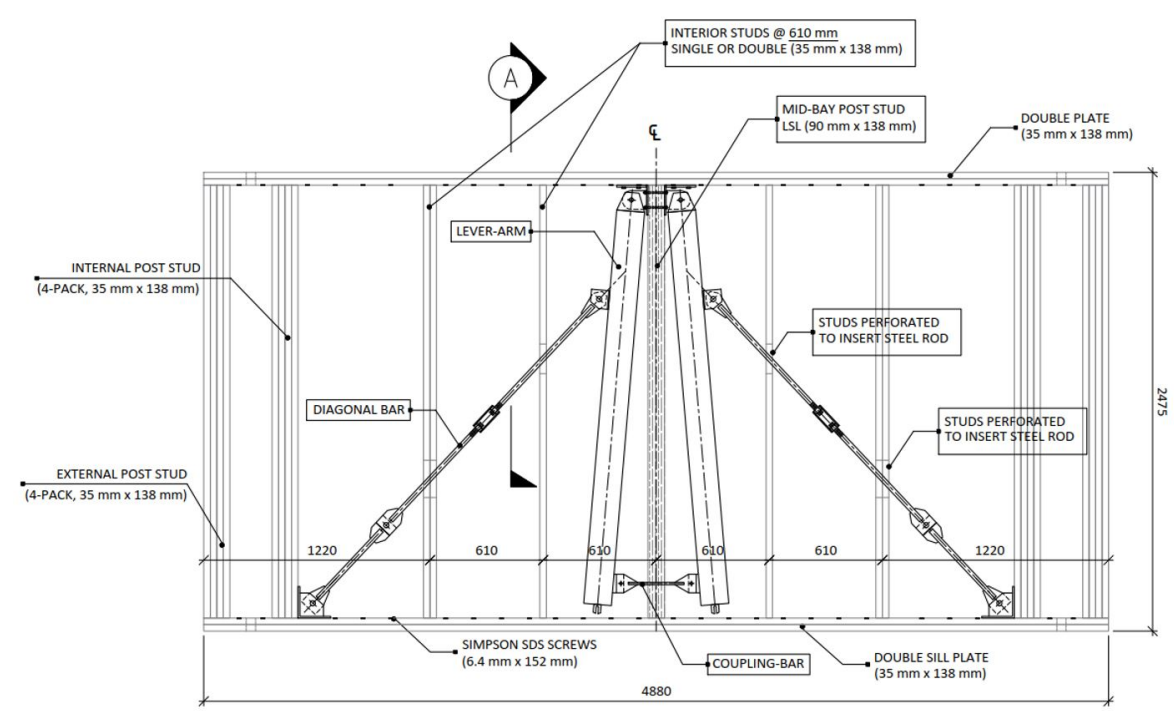

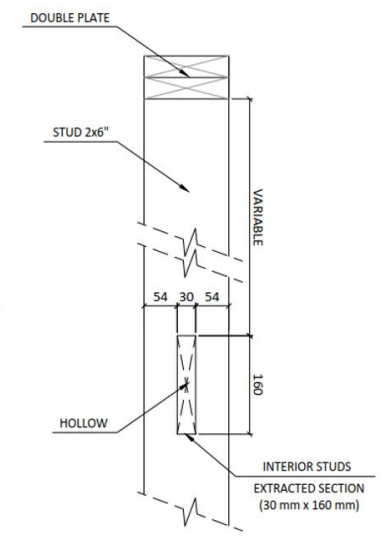

SECTION A-A

Figure 6. Wood-frame shear wall with a double ELAS mechanism.

Some advantages of adopting this amplification mechanism for the wood-frame wall of this research are described below:

- The main reason for employing this $A M$ is that it is easy to install without the need for major changes within the wood-frame structure of the wall. Since its diagonals are thin steel bars, it is possible to install them through the studs without compromising their structural integrity. On the other hand, the lever perfectly fits within the width of the wall, and its amplification range can be adjusted to the maximum spacing between the studs.

- This ELAS mechanism has a great capacity to amplify displacements when compared to other mechanisms. It may theoretically amplify the lateral drift between 7 to 10 times. For comparison, the toggle-brace mechanism amplifies the drift of the structure between 2 to 3 times maximum, the scissor-jack system amplifies the drift between 2 to 2.5 times, and the LAS mechanism has an amplification range of about 5 to 12 times.

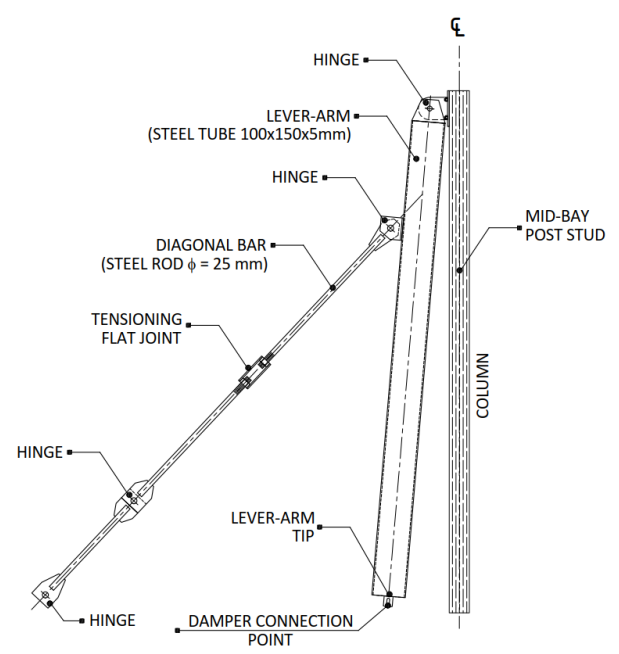

Figure 7. Details of the ELAS mechanism and nomenclature of its components.

All the kinematic associated with the ELAS amplification capabilities and its efficiency levels are detailed in Baquero et al. (2016). Comparing Figures 4 and 6 , it can be noted the changes that had to be made to the wood-frame wall specimen to be able to couple it with the ELAS mechanism: 
- It was necessary to increase the spacing between the interior studs from $400 \mathrm{~mm}$ to $610 \mathrm{~mm}$. This way, the lever has more travel and is able to transmit greater deformations to the damper.

- It was necessary to incorporate a laminated strand lumber (LSL) pile in the center of the shear wall, an element that has a greater shear strength (parallel to grain) necessary to resist the vertical component of the ELAS diagonal bar on the central stud, (vertical shear $V_{V}$ in section 3.4).

- It was necessary to drill the interior studs to install the $25 \mathrm{~mm}$ diameter diagonal steel bars, as shown in Figure 6 (section A-A).

According to Figure 6, the AM in this shear wall specimen was made up of two diagonal bars, two lever arms, and a horizontal bar (coupling bar) that connects the free ends of the two lever arms. This bar goes through a slit made in the central stud of the wall. As previously discussed, the ELAS in Figure 5(a) only works in one direction. For this reason, one ELAS has been symmetrically installed on each side of the central stud of the shear wall but coupled together by a bar connected near the ends of the levers, as shown in Figure 6. The coupling bar connects both levers to make them work together in both directions regardless of which of them is activated by the tensile load. This joint movement of both levers makes it possible to transmit the amplified displacements to the dampers that are placed on each side of the central stud. In addition to the concept of using the coupling bar for each ELAS to work in both directions of lateral movement, this wall specimen included post-tensioning the diagonal ELAS bars at an axial load of $30 \%$ of the steel yield strength. The reason for post-tensioning being that the bars are always stressed so that the lever activates and amplifies the displacement with minimal displacement losses. In addition, once the diagonal bars are prestressed, the ELAS works as a stiffener increasing the lateral stiffness of the shear wall. This is because the tensile load on the diagonal bar activates the lever and transmits a displacement at its end. This displacement is blocked by the damper until the lever applies force with a magnitude equal to the damper yield load. Therefore, as long as the damper does not reach its yield load, all the ELAS components designed to work on the elastic regime will stiffen the shear wall. Consequently, this ELAS system within the shear wall has amplification mechanisms for displacements that are also stiffeners combined with dampers, making up an Amplified Added Stiffening and Damping (AASD) system.

\subsection{Selection of the energy dissipating device: U-shaped Flexural Plates (UFP)}

Although various configurations of metal UFP dissipators have been tested in the literature, the dissipators used in this study were the UFP devices studied and tested by Arizaga and Almazán (2019), who successfully investigated various UFP configurations incorporating an internal restraint system (IRS) to improve the hysterical response. The main characteristics of the damper are presented in the following, for further details the reader is referred to Arizaga and Almazán (2019). The geometric features of the damper are shown in Figure 8(a), including the width $b$, the thickness $t$ of the plate, the mean radius $r$ of the curved section of the device, the free length $L_{L}$ of the wings, and the length $L_{S}$ of the welded wings. According to Arizaga and Almazán (2019), these wings determine the maximum strength, maximum tension, initial stiffness, and the number of cycles before failure. Figure 8(b) shows the IRS, which consists of two A304L stainless steel plates, $2 \mathrm{~mm}$ thick and $50 \mathrm{~mm}$ wide, folded into a $\mathrm{C}$ shape, which are installed to two bronze rollers. The rollers are $38 \mathrm{~mm}$ in diameter and are attached to the C-shaped plates by bolts. The length of the IRS is variable. The goal behind incorporating the IRS is to provide a support surface for the UFPs in order to avoid the change in their geometry from circular to triangular, which is the typical failure mode for this type of device according to the current literature. This " $\mathrm{V}$ " or triangular failure mode results from the local yield of the flexural plate as the hysteretic cycles progress. The intention of using the IRS is to avoid this failure mode. 


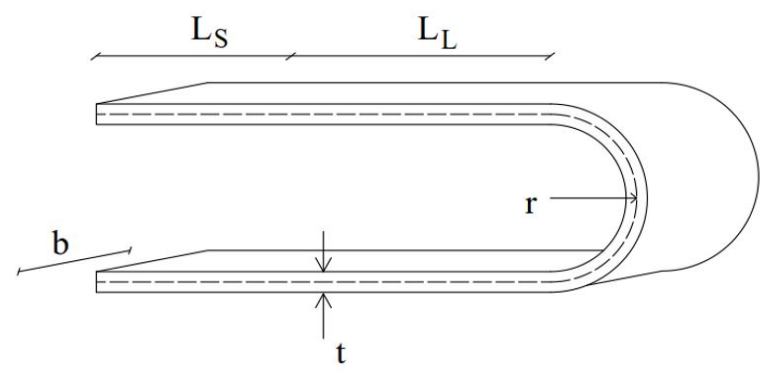

(a)

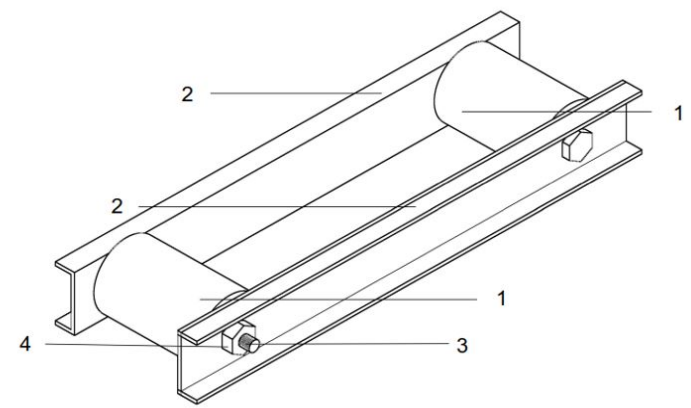

(b)

Figure 8. UFP dissipator from Arizaga and Almazán (2019): (a) geometric variables of the flexural plates, (b) internal restraint system (IRS).

Arizaga and Almazán (2019) tested four UFP specimens, including the IRS (UFP + IRS) and four without including the IRS in order to evaluate its advantages. Figure 9 presents the setup of the tests carried out with and without the IRS, and Table 1 shows the geometric variables of the damper used in that study.

Table 1. Geometric characteristics of UFP tested by Arizaga and Almazán (2019).

\begin{tabular}{ccccccc}
\hline Specimen & $\boldsymbol{t}[\mathrm{mm}]$ & $\boldsymbol{b}[\mathrm{mm}]$ & $\boldsymbol{r}[\mathrm{mm}]$ & $L_{L}[\mathrm{~mm}]$ & $L_{S}[\mathrm{~mm}]$ \\
\hline UFP4 & 2 & 55 & 20 & 205 & 40 \\
\hline
\end{tabular}

Figure 10 shows a comparison between the results of the tests on the UFP dampers, where the contribution of the IRS can be noted. It is observed that including the IRS improves the stiffness and deformation capacity of the damper. Besides, it is observed that the UFP + IRS test also increased its maximum strength and the energy dissipation capacity.

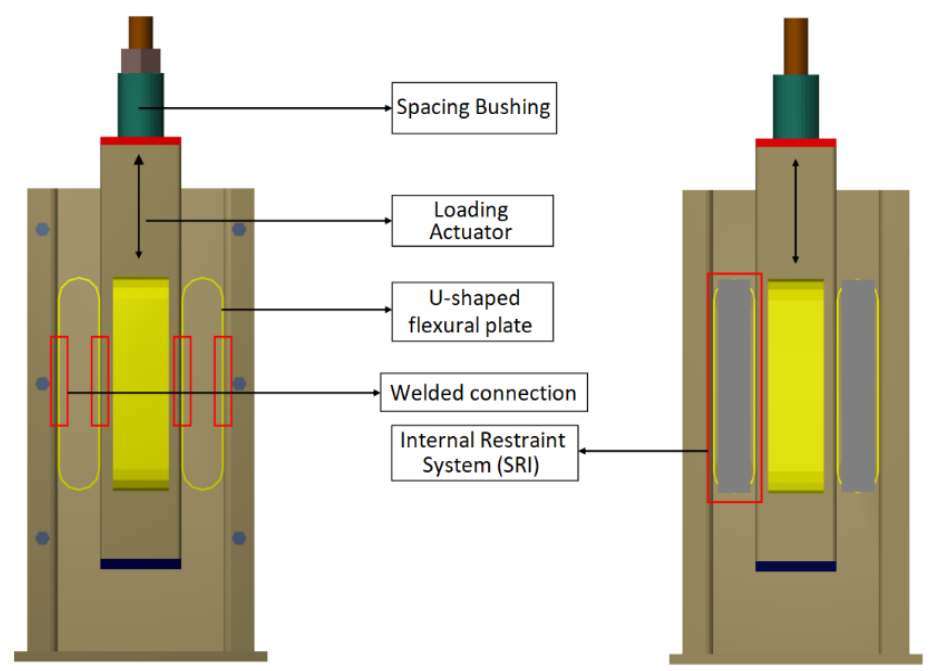

Figure 9. Lateral view of the UFP specimens with and without IRS tested by Arizaga and Almazán (2019). 


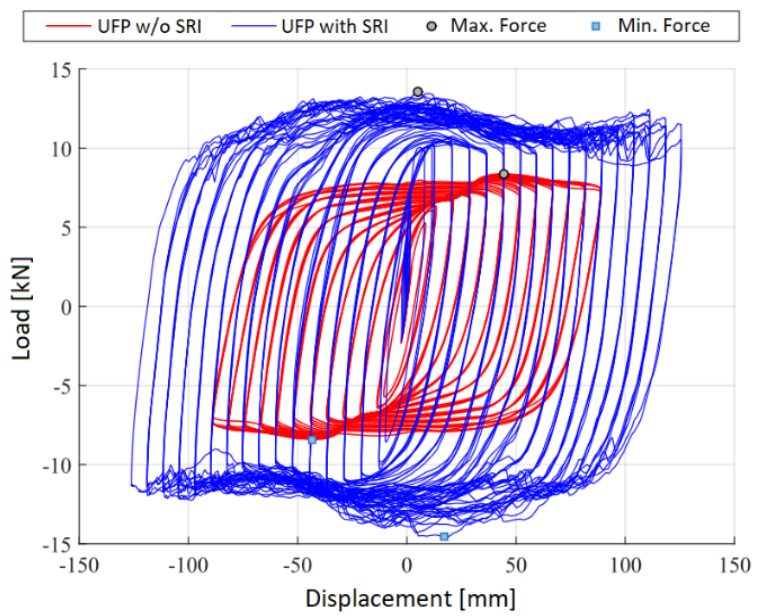

Figure 10. Comparison between load-displacement responses of the UFP devices with and without the IRS.

Arizaga and Almazán concluded that implementing the IRS is advantageous for these dampers allowing the flexural plates to remain rounded even after 200 reversed cycles. Additionally, it was shown that its use increases the strength capacity of the damper, the stiffness during the initial cycles, the number of cycles before failure, and the energy dissipation capacity, especially for devices with a large deformation amplitude. The maximum load recorded during the tests of the UFP + IRS devices was $14.4 \mathrm{kN}$ according to Figure 10, however, as observed in the test setup shown in Figure 9 , this load was resisted by 4 dampers. Thus, the strength of each UFP + IRS device is $3.6 \mathrm{kN}$. It is important to note that the material used for the UFP flexural plates influences the energy dissipation characteristics and hysterical behavior of the specimen. In this case, A304L stainless steel plates were used, which presented a stable cyclic behavior and great ductility capacity. However, carbon steel can also be used to assemble the dampers.

\subsection{Adaptation process between ELAS and the damper within the wood-frame shear wall}

This section describes the procedure to integrate the amplification mechanism ELAS type and the UFP + IRS damper into the wood-frame shear wall specimen. The first step in this process involves designing the connections between the different components of the AASD system with the shear wall. The process to compute the lateral load forces to design such connections is described below.

To design a shear wall in a building employing the amplification mechanism type ELAS coupled with an energy dissipator, it is necessary to define the restoring force required in a given story to resist the lateral force imposed by the earthquake loads, until the drift is reduced to the required level on that story. Subsequently, employing the structural floor plan of the building, the restoring force is divided among the shear walls to which the AASD system will be installed. As a result of this process, the horizontal contributing load $V_{H}$ of each wall with the AASD system is obtained, as shown in Figure 11 (a). In this case, the horizontal design load for the specimen under analysis was equal to $35 \mathrm{kN}$. However, considering that the shear wall had two ELAS mechanisms each equipped with its individual damper, this horizontal load was divided by two, thus obtaining $V_{H}=17.5 \mathrm{kN}$. It is important to note that this load is in addition to the strength load that the shear wall provides considering the thickness of its structural panel and the nailing space. Once $V_{H}$ was defined, the next step was to compute the amplified load $f_{D A M P}$ that the damper needed to bear and the load $R_{D I A G}$ in the diagonal bar. 


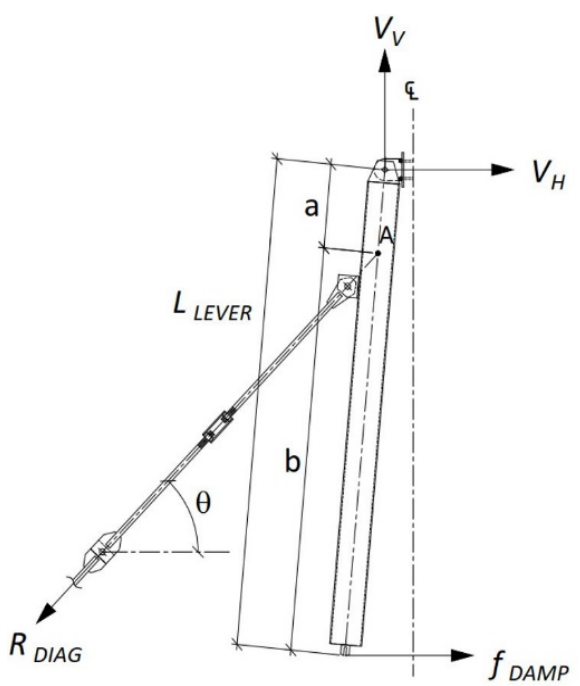

(a)

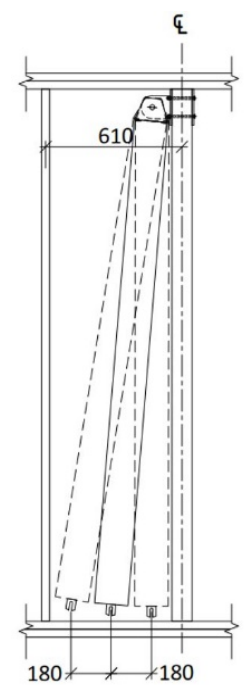

(b)

Figure 11. (a) ELAS free-body diagram, and (b) amplified displacement at the end of the lever.

To calculate the previous loads, it is necessary to compute the moment summation at point A of the ELAS free-body diagram shown in Figure 11(a). Therefore:

$f_{D A M P}=\frac{V_{H}}{b / a}=\frac{V_{H}}{\alpha}$

Where $b / a$ is the amplification factor of the ELAS mechanism called $\alpha=b / a$. The unknowns can now be determined via summation of the horizontal and vertical forces.

$$
\begin{gathered}
R_{D I A G}=\frac{V_{H}+f_{D A M P}}{\cos (\theta)} \\
V_{V}=\sin (\theta) \cdot R_{D I A G}
\end{gathered}
$$

Where the lever length $L_{\text {LEVER }}$ was equal to $2210 \mathrm{~mm}$ taking into account the space available for its installation. On the other hand, $a$ and $b$ are defined considering the displacement amplification factor $\alpha$ of the ELAS mechanism. It is important to note that this factor $\alpha$ physically represents the displacement amplification of the lower end of the lever $\operatorname{arm} U(t)$ from the top displacement of the wall $q(t)$, as shown in Figure 5(b). For instance, if $q=20 \mathrm{~mm}$ and $\alpha$ equal to 5.0, theoretically the amplified displacement in the lever is equal to $U=q \cdot \alpha$, i.e., $U=20 \mathrm{~mm} \cdot(5)=100 \mathrm{~mm}$.

The $\alpha$ factor for wood-frame walls is restrained by the maximum amplified displacement at the free end of the lever (without contacting the vertical studs). As seen in Figure 11(b), a maximum amplified displacement equal to $\pm 180 \mathrm{~mm}$ is adopted for the end of the lever given the $610 \mathrm{~mm}$ spacing between the studs. Therefore, the maximum amplified displacement at the free end of the lever results in a factor $\alpha=4.7$ associated with: $L_{L E V E R}=2210 \mathrm{~mm}$, $a=385 \mathrm{~mm}$ and $b=1824 \mathrm{~mm}$. Thus, solving equations (1), (2), and (3) the resulting loads are:

$V_{H}=17.5 \mathrm{kN} ; f_{D A M P}=3.69 \mathrm{kN} ; R_{D I A G}=32.47 \mathrm{kN} ; V_{V}=25.59 \mathrm{kN}$

These are the loads that the connections between the different components of the AASD system must be able to withstand. Figures 12 and 13 illustrate the design of the relevant connections between ELAS and the wood-frame wall. 

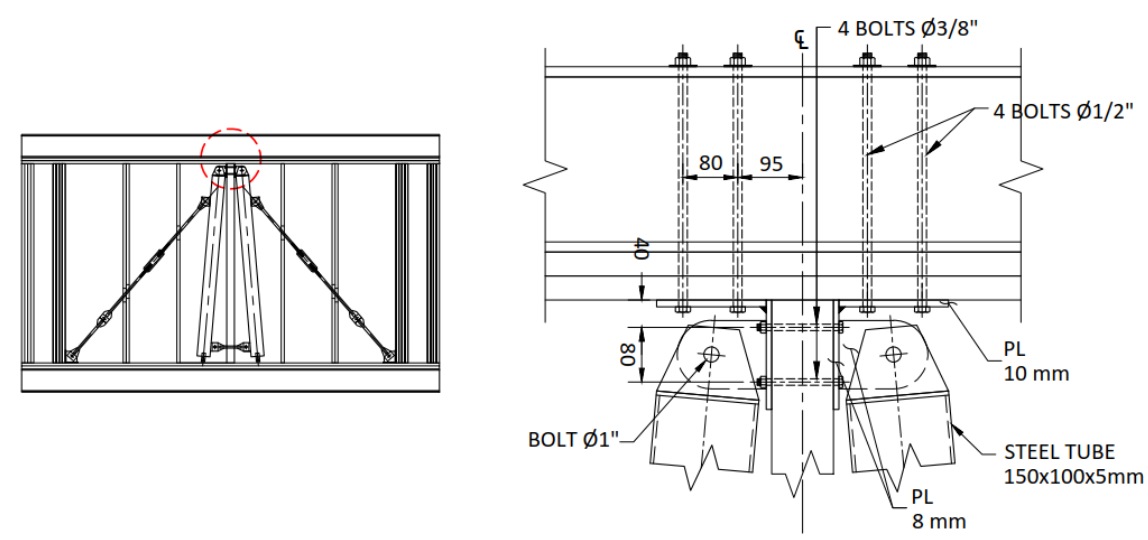

Figure 12. Wall-ELAS connection detail: Upper joint between the central stud, lever, and the floor beam.

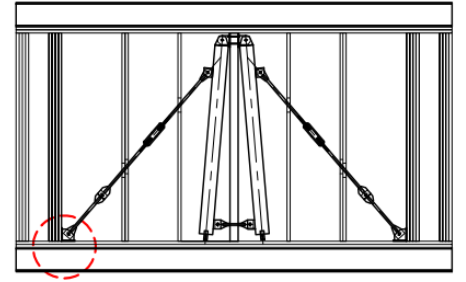

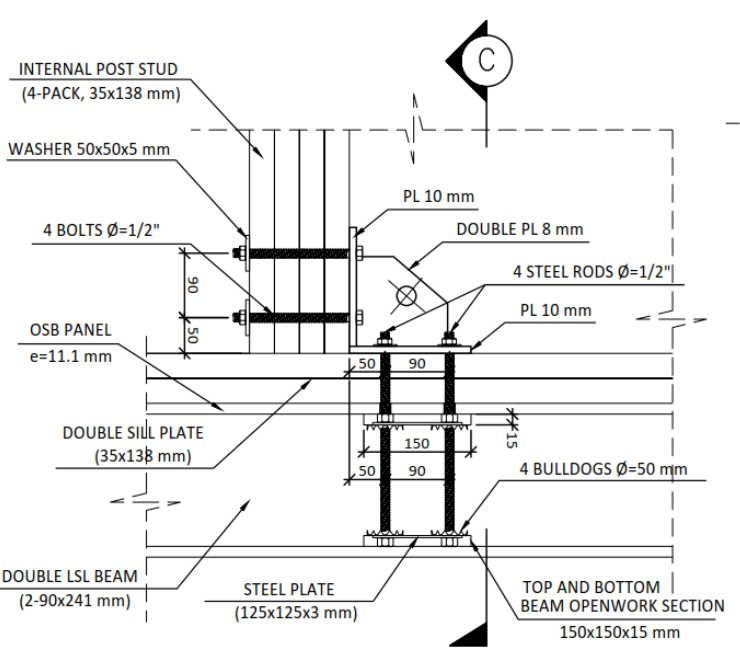

SECTION D-D

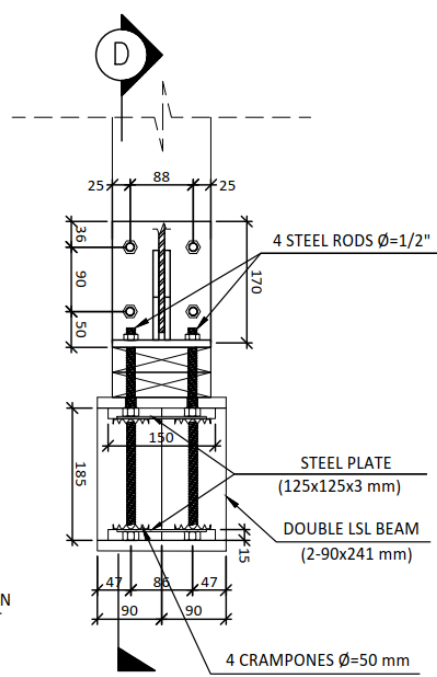

SECTION C-C

Figure 13. Wall-ELAS connection detail: joint between the diagonal bar with the central stud and the floor beam.

The connection between the central stud and the floor beam needed to be pin-ended, but as shown in Figure 12, the presented design curbs the rotation of the central stud. However, at the displacement level to be imposed on the wall, the expected rotations in the central stud are expected very low and should not interfere with the results. Therefore, this connection was finally chosen for the specimen. Although it curbs the rotation of the stud, it is simpler and cheaper than a pin-ended connection at that location. Figure 14 shows the final test specimen that resulted from the integration of the dual ELAS mechanism and conventional wood-frame shear wall with ATS anchorages. 


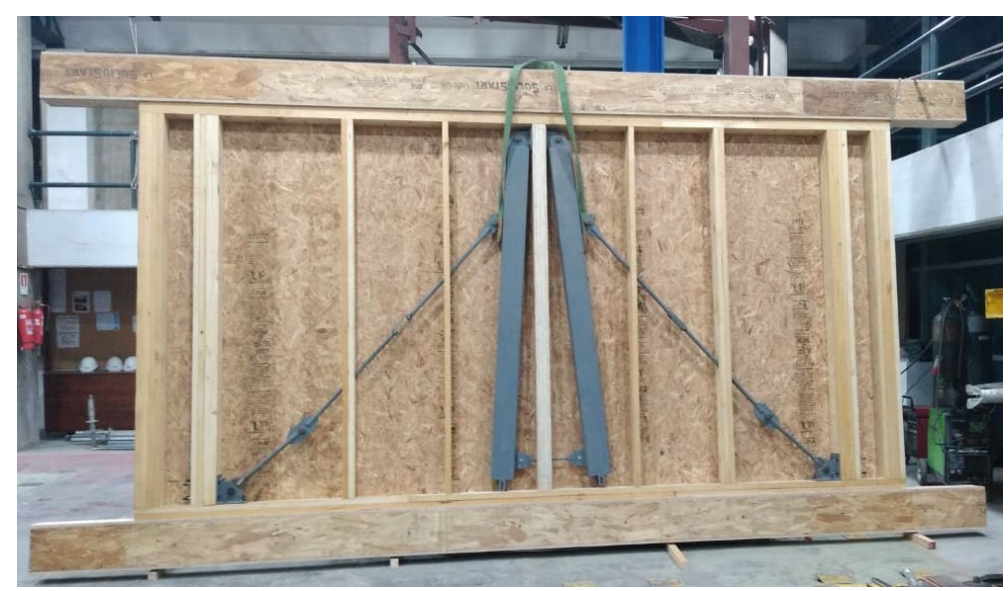

Figure 14. Conventional wood-frame shear wall with double ELAS mechanism prior to the experimental test and the incorporation of the dampers.

The next step consisted of adapting a connection system between the damper and the timber frame of the shear wall. Figure 15 shows the details of the connection between the UFP + IRS damper and the studs of the wall. The damper was placed between two plates that restrict its movement on the \pm Z-axis, allowing its movement only on the $\pm X$-axis. These plates were attached to the studs and sole plates employing self-drilling bolts and screws.
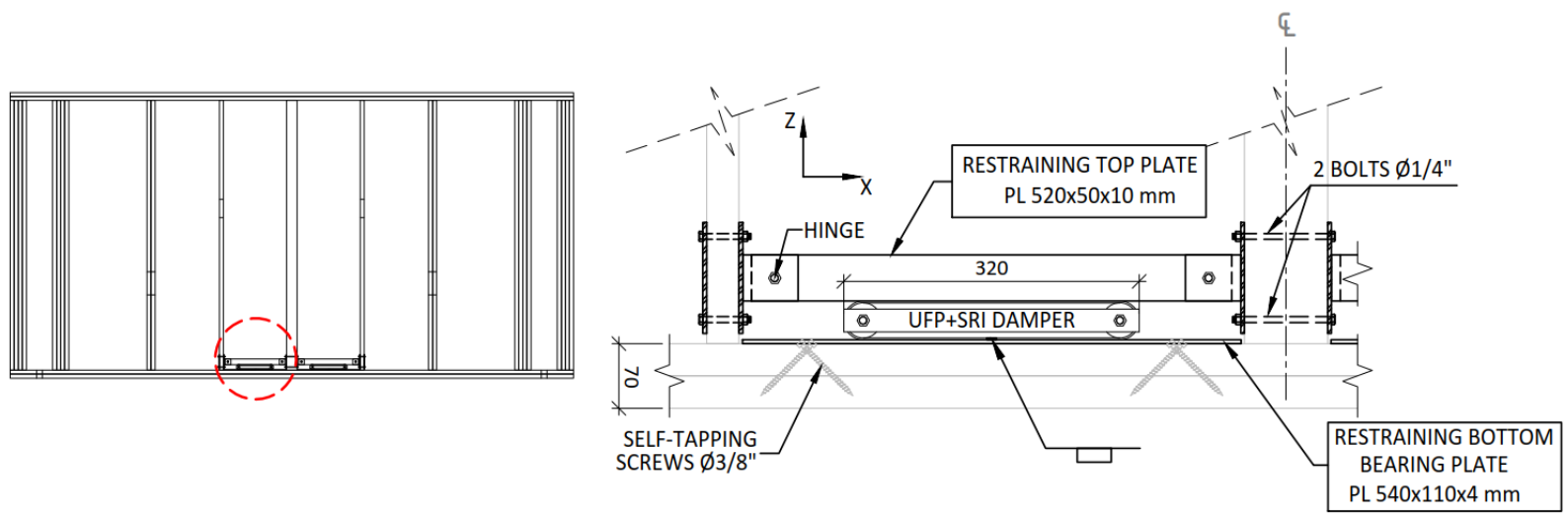

Figure 15. Details of the UFP + IRS damper and its connection to the sole plates and studs of the shear wall.

Once the wall-ELAS connection was defined, the damper connection with the ELAS mechanism needed to be designed. This connection was achieved by connecting a $25 \times 15 \times 3 \mathrm{~mm}$ steel angle to the flexural plate of the UFP using two $\phi 1 / 4$ " diameter bolts, as shown in Figure 16. The steel angle has welded a smooth steel rod $25 \mathrm{~mm}$ in length and $\phi 1 / 2$ " diameter, this rod is the connection point of the UFP + IRS damper with the lever arm of the ELAS mechanism, as can be seen in Figure 17. As shown in Figure 16, the damper used in this study was small, which made it perfect to be used in wood-frame shear walls considering that there was a restriction on the width available within the timber frame. Among its other advantages, this damper is a very economical device, simple to assemble, and easy to install inside the structure of the shear wall. Figure 17 shows the scheme and a photo of the UFP + IRS damper with its connection to the lever arm of the ELAS mechanism. This connection was achieved by means of a steel flange welded at the bottom of the lever arm, thus forming the damper connection point (see Figure 7) in which the $\phi 1 / 2$ " smooth steel rod was inserted. Steel rod that was mechanically joined to the damper employing a steel angle, as indicated in section E-E in Figure 16. 

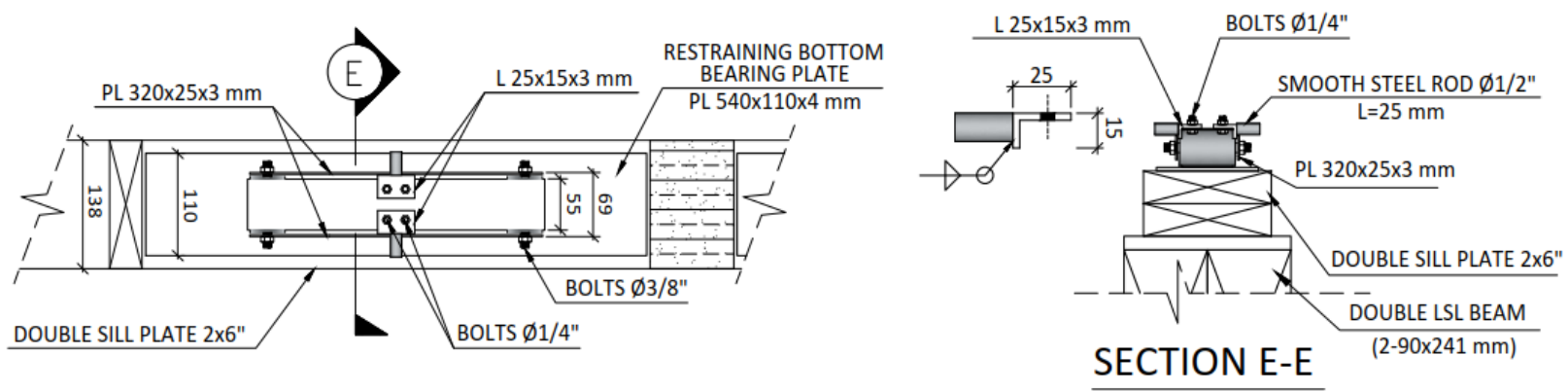

Figure 16. Details of the UFP+IRS damper adapted to connect to the lever arm of the ELAS mechanism (the top restraining plate and its mounting elements are not shown for simplicity).
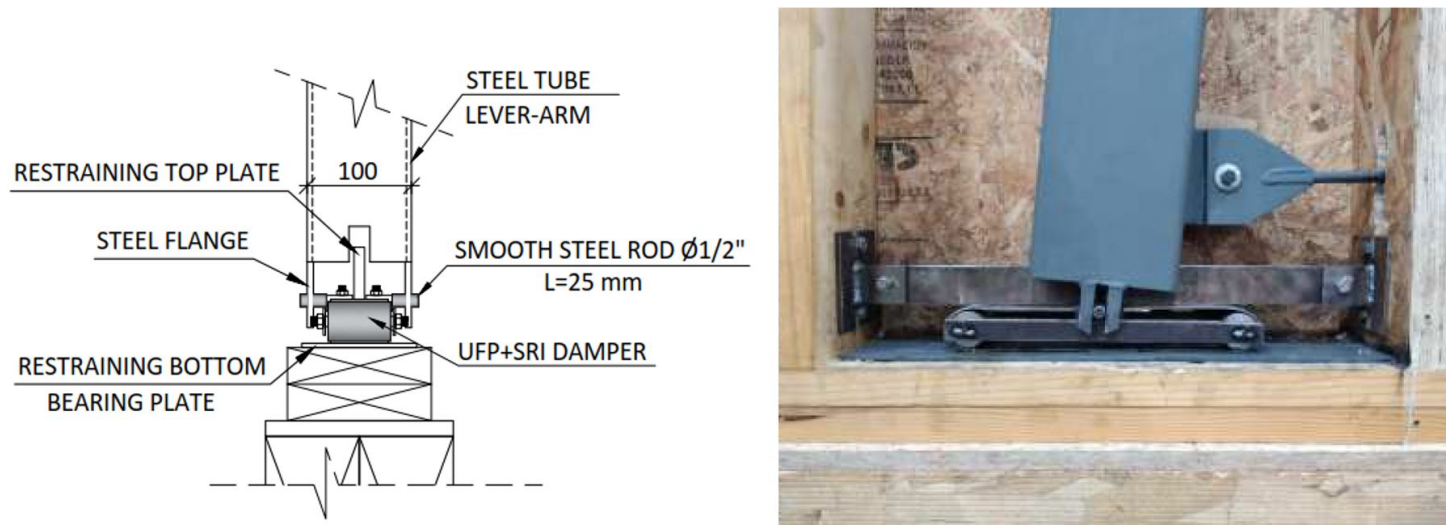

Figure 17. Details of the connection between the UFP+IRS damper and the lever arm of the ELAS amplification mechanism.

\section{DESCRIPTION OF TESTED SPECIMEN AND TESTING SET UP}

In order to collect information to answer the second research question regarding the behavior and real effectiveness of the proposed AASD system when it was integrated into a wood-frame shear wall, a set of pseudo-dynamic tests were carried out to experimentally evaluate the performance of the specimen when subjected to reversed cyclic lateral loads. Additionally, this allowed a better understanding of its seismic behavior and the development of an experimental database for future numerical models.

\subsection{Test specimen overview and test setup}

Figures 18 and 19 present the test setup. The test specimen consisted of a typical wood-frame shear wall $4880 \mathrm{~mm}$ long and $2475 \mathrm{~mm}$ high (Figure 6). The test specimen's top and bottom plates were connected to two 241x90mm laminated strand lumber (LSL) beams employing $\phi 1 / 4$ " $\times 6$ " Simpson Strong-Tie SDWS screws spaced at $150 \mathrm{~mm}$ on center. These double LSL beams were the elements connected to the hydraulic actuator responsible for providing the controlled cyclical lateral displacements. The hydraulic actuator has a displacement range of $\pm 200 \mathrm{~mm}$ and a capacity of $1000 \mathrm{kN}$. No vertical load was applied during the test. 


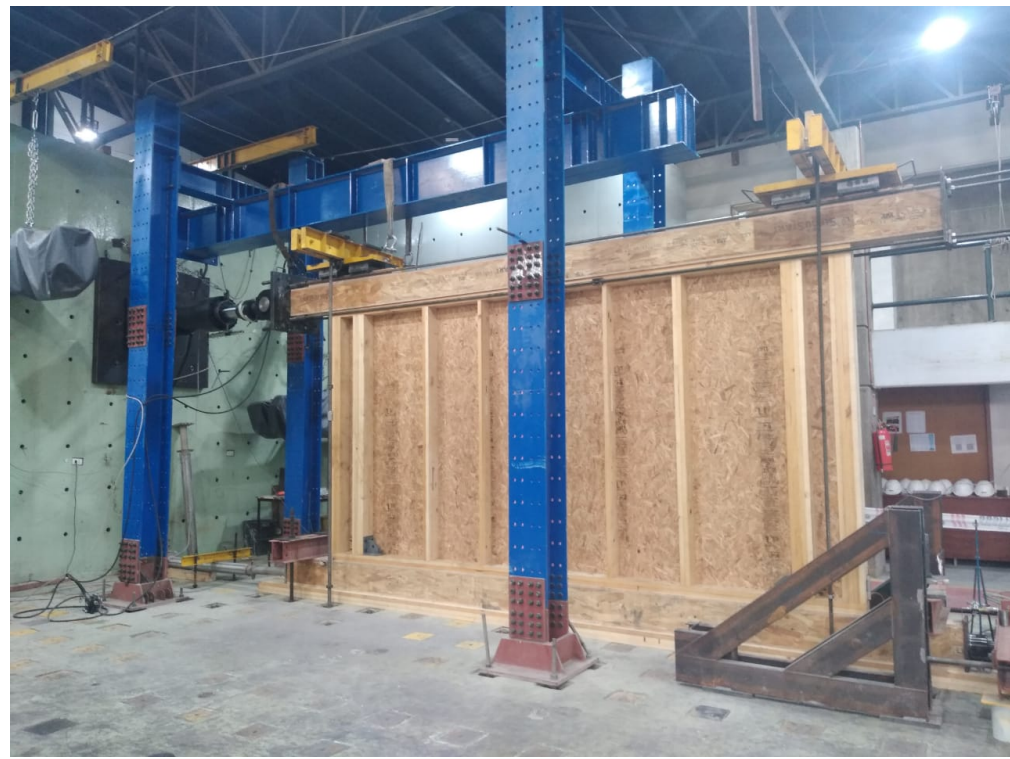

Figure 18. Test setup of the shear wall specimen before installing the double ELAS mechanism, dampers, and instrumentation (the blue frame shown in the picture is not part of the test setup).

The timber frame of the shear wall was made up of $1.5^{\prime \prime} \times 5.5(35 \times 138 \mathrm{~mm})$ studs and plates. The interior studs were spaced at $610 \mathrm{~mm}$ on center. The wood employed for the studs was mechanically graded MGP10 Chilean Radiata Pine. The central stud was a 138x90 mm LSL member. The internal and external studs were made up of a pack of four $35 \times 138 \mathrm{~mm}(140 \times 138 \mathrm{~mm}$ in total) studs, which were mechanically joined by nails to form a single structural element according to the guidelines provided in Section 15.3 of the NDS-2018 standard. OSB panels were $18 \mathrm{~mm}$ thick of sheathing grading, connected to the studs employing $\$ 3 \mathrm{~mm} \times 70 \mathrm{~mm}$ spiral nails spaced at $100 \mathrm{~mm}$ on center. OSB panels were installed only on one side of the shear wall.

As presented in Figures 18 and 19, the ATS anchorages were not included in the test setup for simplicity of implementation. This was because it was challenging to match the position of the ATS steel rods within the wall specimen with the exact location of the pre-existing anchor grid (spaced at $500 \mathrm{~mm} \times 500 \mathrm{~mm}$ ) of the reaction slab in the laboratory. However, the same hold-down mechanism was achieved via steel bars and transversal beams (in yellow in Figure 18) outside the wall were used to fix it to the ground and minimize the overturning effects on global drift measurements. Such overturning restriction externally imposed by the beams and steel bars contributed to generating a self-centering effect on the shear wall too. Below the beams, rollers were installed to allow the wall to move freely on its own plane.

\subsection{Instrumentation and testing procedures}

The data acquisition system consisted of 24 channels installed to receive the specimen measurements regarding the applied load, displacement transducers, and unit deformation recorded by strain gauges placed on the diagonal steel bars (SG1 and SG2). The positions of the LVDTs are shown in Figure 19. The shear wall specimen with the AASD system was tested in four phases with two different configurations. Two phases were tested with a first configuration without the ELAS or the damper. These tests were a basis to evaluate the contribution of the AASD system to the performance of the shear wall. Subsequently, two phases were tested with the second configuration including the ELAS and the damper. Table 2 presents a summary of the phases and configurations tested.

Phases 2 and 4 comprised re-testing the specimen after completion of the previous experimental phase without any repair. That is, the OSB panel was not replaced, nor new nails were installed. Both the OSB panels and the nails were left with the existing damage after the previous test 


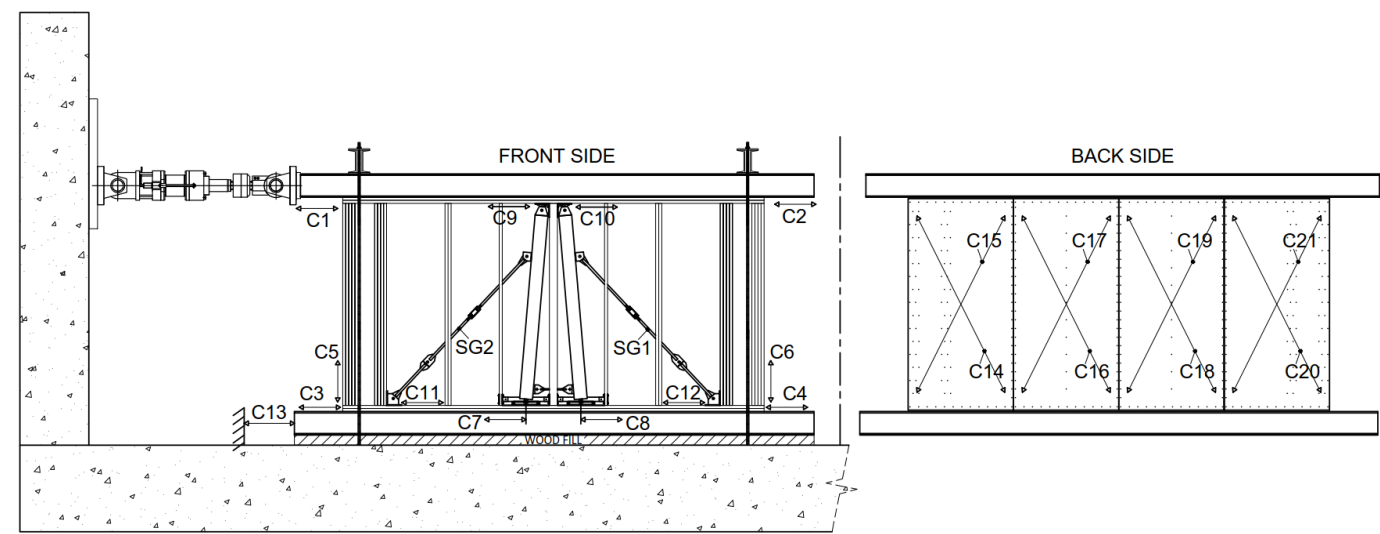

Figure 19. Elevation view of shear wall specimen with its instrumentation.

Test phases 2 and 4 were carried out to get to know the contribution of the AASD system on a wood-frame shear wall when it has been severely damaged, which allows a better understanding of its post-earthquake performance. Comparisons using the experimental results of phases 2 and 4 allowed to analyze the resilience that the AASD system offered in terms of residual strength, stiffness, and damping. Degradation quantification is especially relevant in wood shear walls due to strength and stiffness degradation under large displacement.

Table 2. Schedule of testing phases and test specimen configurations.

\begin{tabular}{ccc}
\hline Test Phase & Specimen Configuration & Sheathing and Nailing State \\
\hline 1 & Wall without ELAS and damper installed & Sheathing new. Initial driven nails. \\
2 & Wall without ELAS and damper installed & Unrepaired sheathing. Nailing as remained from previous test. \\
3 & Wall with ELAS and damper activated & Sheathing new. New nails were installed. \\
4 & Wall with ELAS and damper activated & Unrepaired sheathing. Nailing as remained from previous test. \\
\hline
\end{tabular}

Cyclic tests were performed using the CUREE-Caltech loading protocol following the ASTM-E2126 Method C. However, the loading protocol used in test phases 1 and 2 was different from that applied in phases 3 and 4 . These last phases had a maximum lateral displacement of less amplitude and more cycles at the beginning of the protocol (see Figure 20). This is because the ELAS lever arm maximum displacement is restrained by the studs' spacing. As shown in Figure 11(b), the maximum amplified displacement for the lever arm at its end was $\pm 180 \mathrm{~mm}$.

In order to test the effectiveness of the damper, 10 reversed cycles in steady-state at their maximum deformation were applied during phases 3 and 4. To find the level of lateral displacement of the wall that imposes the maximum deformation on the dampers, lateral trial displacements were carried out employing the hydraulic actuator. It was found that at a lateral displacement of $\pm 61 \mathrm{~mm}$ at the top of the wall, the lever arm amplified at its end the $\pm 180 \mathrm{~mm}$ chosen as maximum displacement. For this reason, the cyclic protocol in phases 3 and 4 was brought up to a maximum lateral displacement of $\pm 61 \mathrm{~mm}$, as shown in Figure 20 .
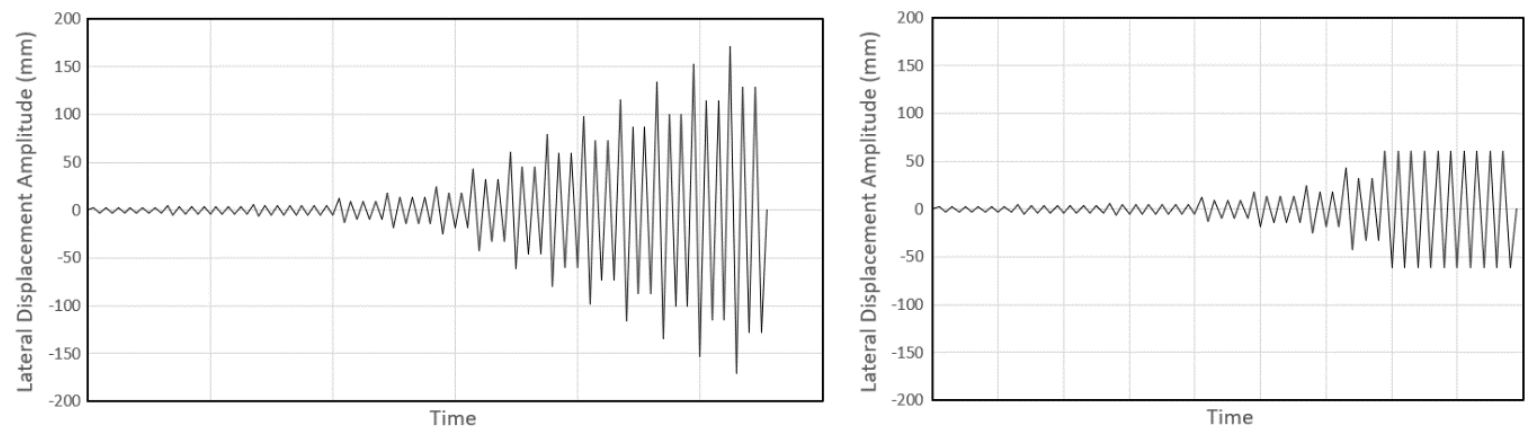

Figure 20. Cyclic testing protocols for phase 1 y 2 (Left), and phase 3 y 4 (Right).

During the trial of reaching $\pm 180 \mathrm{~mm}$ of amplified displacement at the end of the lever arm by applying $\pm 61 \mathrm{~mm}$ to the top, it was found that the joints between the ELAS mechanism and the timber frame of the shear wall behaved to 
flexible. This flexibility of the joints and the losses that it generated in the deformation capacity of the dampers were therefore reassessed and a new stiffer joining technology was chosen, which is presented in the following.

\section{ANALYSIS AND DISCUSSION OF THE EXPERIMENTAL}

\subsection{Evaluation of the losses in the transmission of displacements from the shear wall to the damper}

The concentration of stresses at the joints, in addition to the inherent flexibility of the connections in timber frames, had a relevant potential to decrease the efficiency of the damper system due to displacement losses. In section 3.4, it was noted that the displacement amplification factor of the ELAS mechanism in this study was $\alpha=4.7$. However, as discussed above, a top wall displacement of $\pm 61 \mathrm{~mm}$ was required to achieve the $\pm 180 \mathrm{~mm}$ of amplified displacement at the end of the lever. Hence, the real amplification factor $\alpha$ of the system was $\alpha=180 \mathrm{~mm} / 61 \mathrm{~mm}=2.95$, which, being much less than the theoretical factor $\alpha=4.7$, shows that there are significant losses due to flexibility in the joints between the ELAS mechanism and the shear wall. Therefore, the total loss (that can be measured from the experimental data) in the first lateral test was about $37.2 \%$. This is consistent with the report by Hwang et al. (2005) who noted displacement transmission losses of about $40 \%$ and with the results from Shinde and Symans (2010) who estimated displacement losses ranging from 30 to $40 \%$ due to the flexible frame members and joints of timber structures.

The measurement of these losses in the transmission of the displacement from the shear wall to the ELAS mechanism was possible through an analysis of the data from the LVDT sensors installed in channels C9, C10, C11, and $\mathrm{C} 12$, as shown in Figure 19. Channels C9 and C10 measured the relative displacement between the top plate and the steel plates of the union in the central stud (see Figure 12). Channels C11 and C12 measured the relative displacement between the steel plate at the diagonal bar and the bottom plate (see Figure 13). Therefore, once phases 1 and 2 had been carried out and when phase 3 was getting started, significant measurements were detected in channels $\mathrm{C} 9$ to $\mathrm{C} 12$, showing relative displacements that forced phases 3 and 4 to be postponed until controlling these sources of flexibility in the system.

Figure 21 shows the reinforcements installed to stiffen the union at the central stud with the floor beam, while Figure 22 shows the reinforcement in the steel plate at the diagonal bar union with the bottom plate. In both cases, it was necessary to weld an extension of the horizontal steel plates in contact with the timber plates to install self-drilling screws in diagonal. The reinforcement at the central stud required installing $4 \mathrm{VGZ}$ screws ( $\$ 7 \mathrm{~mm} \times 260 \mathrm{~mm}$ ) at $45^{\circ}$ on each side of the central stud ( 8 in total) in order to control the relative displacement between the connections of the amplification mechanism and the timber plates. In the same way, the reinforcement of the diagonal bar also required installing $4 \mathrm{VGZ}$ screws at $45^{\circ}$ at each connection point of each diagonal bar. However, due to the existence of other previously installed connections (see Figures 12 and 13), it was not possible to install all the required VGZ screws considering that these would coincide with the $\phi 1 / 2^{\prime \prime}$ steel bolts and bars, and with the $\phi 1 / 4^{\prime \prime} \times 6$ " Simpson Strong-Tie SDWS screws that make up the shear connection between the double LSL beams and the timber plates. For this reason, only 3 VGZ screws were installed on each side of the central stud instead of the required 4 , and 3 screws at the joints of the diagonal bars with the timber plates. Therefore, it was only possible to limit the relative displacements of these connections and not to control them completely, as will be seen later in Figure 23.

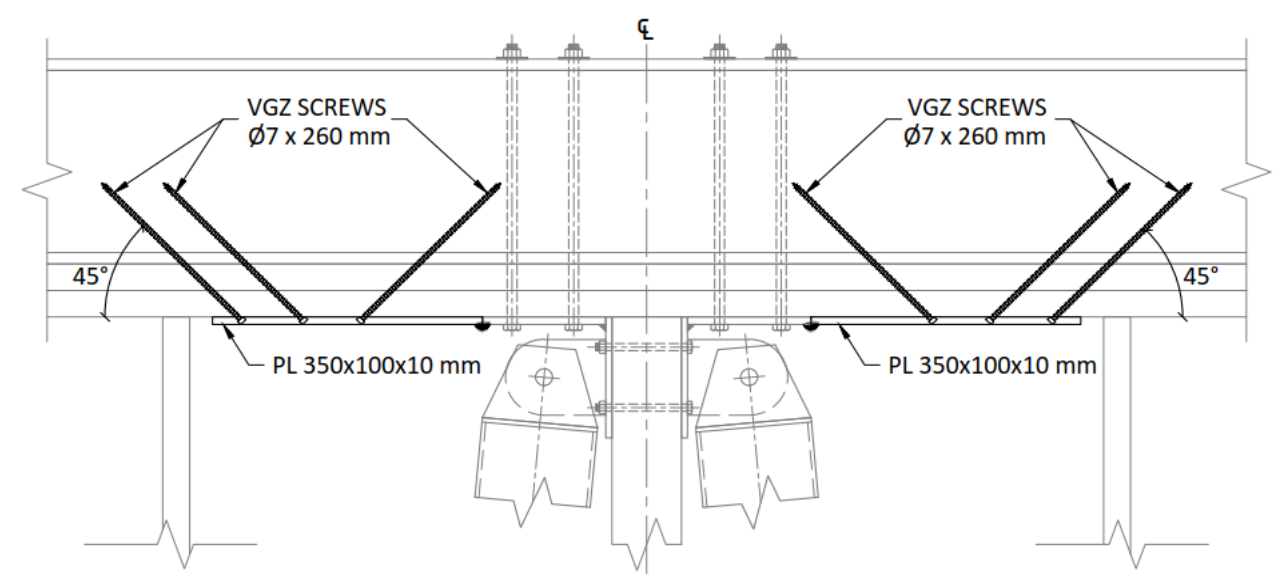

Figure 21. Reinforcement and stiffening of the upper connection between the central stud and floor beam. 


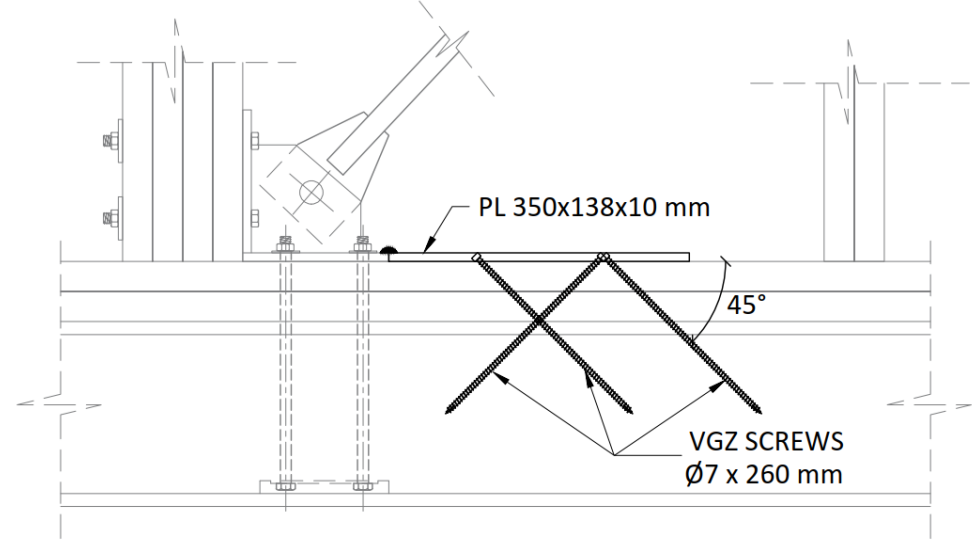

Figure 22. Reinforcement and stiffening of the connection between the steel plate of the diagonal bar union and the bottom plate.

Figure 23 shows the results of the implemented reinforcements, where the relative displacements measured during phase 3 by the channels C9, C10, C11, and C12 (located according to Figure 19) are shown. It can be noted that because fewer VGZ screws were installed than those required by design, there are still relative displacements at these connection points. However, they were much smaller than the initial configuration and deemed stiff enough to test the wall.
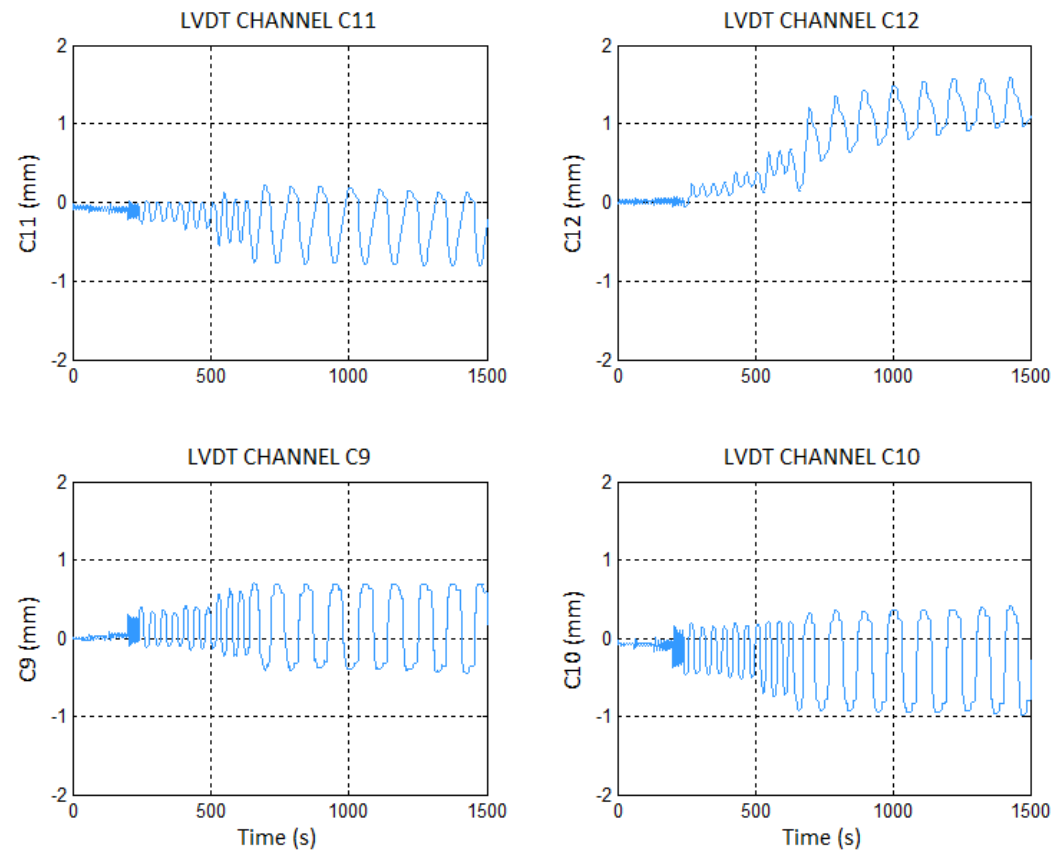

Figure 23. Relative displacements measured by transducers located in channels C9 to $C 12$ during test phase 3.

\subsection{Testing results and discussion}

The hysteresis curves measured at the shear walls specimens are shown in Figure 24. From the test results, a clear increase of stiffness was evidenced for the damped system both in pre- and post-earthquake scenarios. The increase of the effective stiffness and strength for the damped wall against the undamped wall was about $13 \%$ for the initial testing and nearly $500 \%$ higher in the post-earthquake scenario. This stiffening effect is of great importance for these types of buildings as the interstory drift is commonly the primary design constraint. Similar increases were also found in the strength, which becomes especially important aftershock because the residual strength of wooden shear walls is typically very low, as evidenced by the response of the shear wall at phase 2 . In fact, a dramatic drop of stiffness and strength of about $87 \%$ was found for the undamped shear wall aftershock (phases 2 and 4), whereas the equivalent drop for the damped system was $42 \%$. That increase of strength and stiffness would be critical in post-seismic events, greatly increasing the resilience of the system. The drops of stiffness and strength were also evidenced at undamaged shear walls during the first testing phases (phase 1 and 3), showing that for large-amplitude cycles, the loss of strength and stiffness in the undamped shear walls was about $70 \%$ whereas for the damped wall it was limited to $40 \%$. The lesser 
drops in strength and stiffness mean that even when the nails can be heavily damaged in both configurations due to very large displacements, the damped system still can provide significant strength and stiffness, even when the lateral contribution of the nails may become virtually negligible, as evidenced by the lateral capacity at phase 2 .
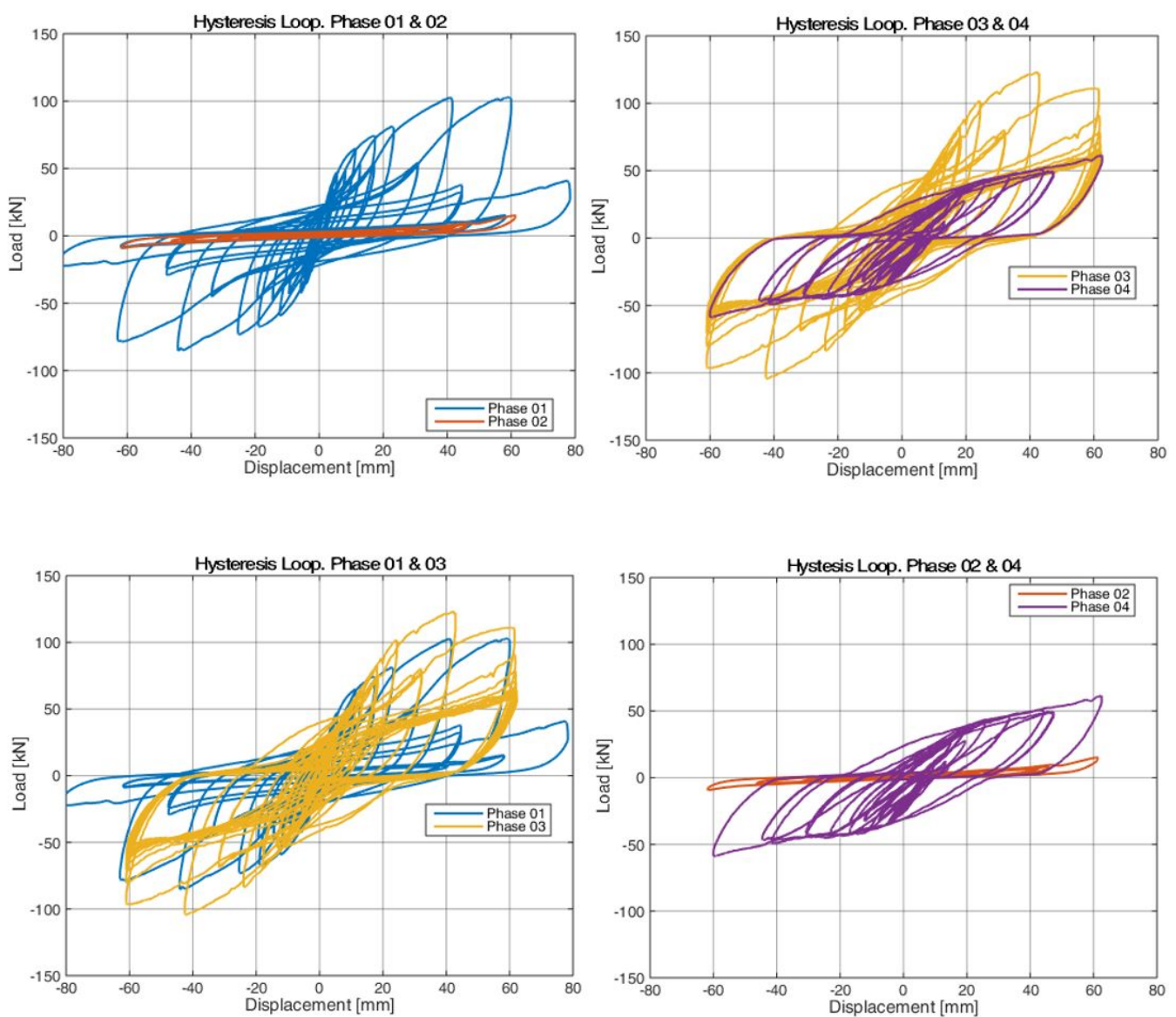

Figure 24. Comparison of the shear wall cyclic response between the different phases, including a comparison of the undamped performance of the wall before and after a major earthquake (left above); comparison of the damped wall pre and post-earthquake (right above); comparison of undamped vs. damped wall before (left below) and after an earthquake (right below).

The significant lesser stiffness and strength drops of the damped system consequently reduced the pinching hysteresis behavior, which is typical of wooden shear walls. Such a decrease in pinching led to much larger energy dissipation capabilities, which is evidenced in Figure 25. The energy dissipated by the damped shear wall was $32 \%$ larger in comparison to the undamped shear wall during the first testing phase. Such an increase turned more evident for the post-earthquake scenario, where the increase of energy dissipation was 4 times larger for the damped system. The decrease of energy dissipation for each configuration aftershock was $91 \%$ for the undamped system and $40 \%$ for the damped shear wall.

It is also interesting to compare the characteristics of the intact shear wall (phase 1) versus the damaged damped wall after two extreme earthquake scenarios (phase 4). The results in this investigation demonstrated that the damped walls, even after two major earthquakes, still can be providing about $2 / 3$ of the initial stiffness and strength and about $80 \%$ of energy dissipation capabilities in comparison to intact undamped timber shear walls. However, without damping, the shear wall would be suffering drops of $87 \%$ in strength and stiffness and $91 \%$ in energy dissipation. This simple comparison proves that even when the energy dissipation of wooden shear walls can be assumed as 'high', a damping system still makes a significant difference, especially when considering potential aftershock earthquakes. Another important improvement in resilience was also evidenced by the damping ratio. Although the damping of the undamped $(18,24 \%)$ and damped systems $(20,86 \%)$ were relatively similar, a dramatic drop was observed aftershock for the undamped shear wall $(11,65 \%)$, while the damping for the damped system even increased due to the critical role of the damper after damage $(21,34 \%)$. The summary of all numerical results is shown in Table 3. 


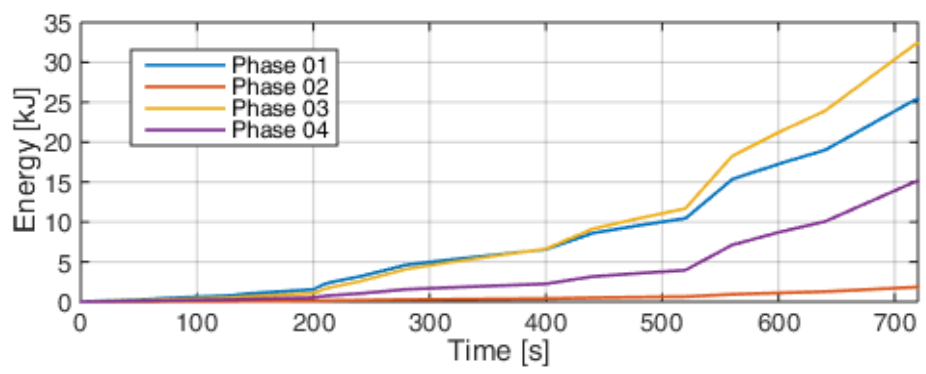

Figure 25. Energy dissipated by the sherar wall in each test phase for a lateral displacement equal to $61 \mathrm{~mm}$.

Table 3. Test phase comparisons (at a $61 \mathrm{~mm}$ displacement amplitude).

\begin{tabular}{cccc}
\hline Test Phase & $K_{\text {eff }}[\mathrm{kN} / \mathrm{mm}]$ & $\mathrm{E}_{\mathrm{d}}[\mathrm{J}]$ & $\xi_{[\%]}$ \\
\hline 1 & 1.51 & 6284.66 & 18.24 \\
2 & 0.20 & 552.66 & 11.65 \\
3 & 1.71 & 8288.33 & 20.86 \\
4 & 0.99 & 4950.50 & 21.34 \\
\hline
\end{tabular}

Even when a major improvement of the structural behavior was found for the damped configuration, the measurements of the amplificated displacements of the damper versus the lateral displacements of the shear wall were less efficient than expected. The anticipated amplification ratio for the ELAS system was about $\alpha=4.7$. However, the measured displacement amplification was about 3.0, dropping up to 2.2 for very large displacements. See a comparison of the interstory drift versus the displacement at the damper in Figure 26. The main reason for such a reduced efficiency in the displacement amplification is not attributed to possible flexibilities at the joints between the ELAS system and the timber frame, but to the connections of the amplification system itself. As illustrated in Figure 27, significant plastic deformation due to an embedment of the connector at the diagonal bar in the ends of the wall was observed. In addition, a partial failure of the welded steel joint at the connection between diagonal bars and lever arms was also evidenced. However, there was no visible damage at the connections jointing the amplification system with the timber frame. These results indicate that there is potential to improve the efficiency of amplification systems by simply oversizing the diagonal and lever arm components, which consequently should increase not only the efficiency of the displacement amplification ratio but also the resilience, as lesser drops of strength, stiffness, and energy dissipation capabilities are expected.

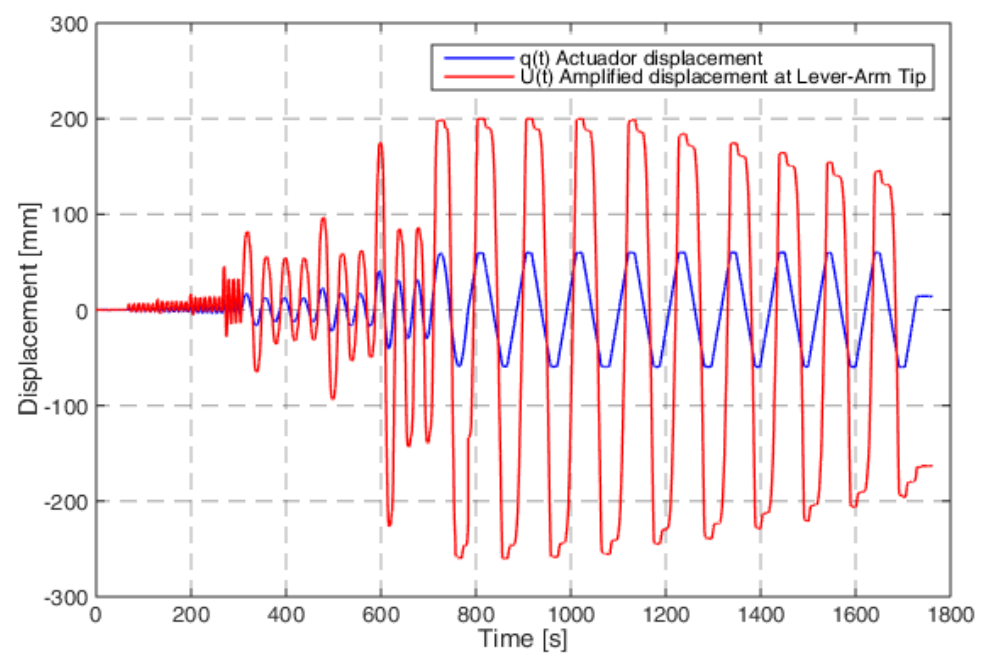

Figure 26. Displacement amplification at the end of the lever arm of the ELAS mechanism compared to the overall lateral displacement at the top of the shear wall (phase 3). 

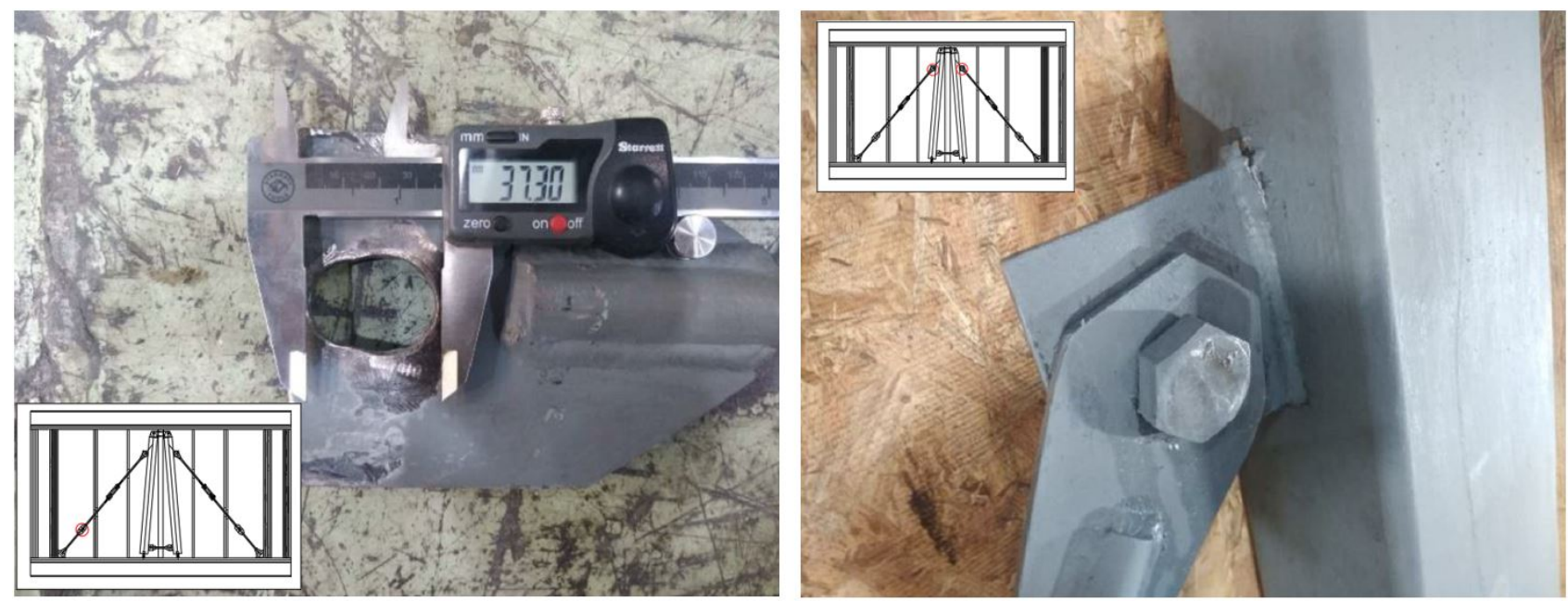

Figure 27. Plastic deformations at the connections of the amplification system due to design flaws.

\section{APPLICATION OF THE AASD SYSTEM TO A MDOF WOOD-FRAME STRUCTURE}

This section analyzes the application of the proposed AASD system in the vertical plane of a mid-rise building in order to assess: i) the reduction interstory drifts, and ii) estimate the level of contribution of the AASD system to improve the lateral performance of the shear walls of 6 -story wood-frame buildings. For such purpose, a simple structural model was implemented, in which each floor of the MDOF system was made up of $4880 \times 2440 \mathrm{~mm}$ wood-frame shear walls. The elastic stiffnesses of the shear walls were obtained from Equation 4.3-1 of the SDPWS standard (American Wood Council 2015).

The geometric characteristics and mechanical properties of the elements that make up the shear walls of each floor, and from which the lateral stiffness of each floor was obtained is presented in Table 4.

Table 4. Geometry and mechanical properties of the shear wall components.

\begin{tabular}{|c|c|c|c|c|c|c|c|c|c|c|c|}
\hline Shear Wall & $\begin{array}{c}\mathrm{E}_{\mathrm{f}} \\
{[\mathrm{MPa}]}\end{array}$ & $\begin{array}{c}E_{A T S} \\
{[\mathrm{MPa}]}\end{array}$ & $\begin{array}{l}\mathbf{b}_{\text {WALL }} \\
{[\mathrm{mm}]}\end{array}$ & $\begin{array}{l}h_{\text {WALL }} \\
{[\mathrm{mm}]}\end{array}$ & $\begin{array}{c}t_{\text {DIAPHRAGM }} \\
{[\mathrm{mm}]}\end{array}$ & $\begin{array}{c}A_{\mathrm{EXT}} \\
{\left[\mathrm{mm}^{2}\right]}\end{array}$ & $\begin{array}{c}A_{\mathrm{INT}} \\
{\left[\mathrm{mm}^{2}\right]}\end{array}$ & $\begin{array}{c}\text { eosB } \\
{[\mathrm{mm}]}\end{array}$ & $\begin{array}{l}\text { S }_{\text {NAILS }} \\
{[\mathrm{mm}]}\end{array}$ & $\begin{array}{c}\mathbf{G}_{\mathrm{a}} \\
{[\mathrm{kN} / \mathrm{mm}]}\end{array}$ & $\begin{array}{c}\phi_{\text {ATS }} \\
{[\mathrm{mm}]}\end{array}$ \\
\hline W101 & 10000 & 205940 & 4880 & 2440 & 338 & 19320 & 19320 & 11.1 & 50 & 7.355 & 34.9 \\
\hline W201 & 10000 & 205940 & 4880 & 2440 & 338 & 19320 & 19320 & 11.1 & 50 & 7.355 & 28.6 \\
\hline W301 & 10000 & 205940 & 4880 & 2440 & 338 & 19320 & 19320 & 11.1 & 75 & 4.904 & 25.4 \\
\hline W401 & 10000 & 205940 & 4880 & 2440 & 338 & 19320 & 19320 & 11.1 & 75 & 4.904 & 22.2 \\
\hline W501 & 10000 & 205940 & 4880 & 2440 & 338 & 19320 & 19320 & 11.1 & 75 & 4.904 & 19.1 \\
\hline W601 & 10000 & 205940 & 4880 & 2440 & 338 & 19320 & 19320 & 11.1 & 100 & 3.853 & 9.5 \\
\hline
\end{tabular}

Where:

$E_{f}$ : Modulus of elasticity of end post studs [MPa].

$E_{A T S}:$ Modulus of elasticity of Strong-Rod ATS anchor steel rods [MPa].

$b_{\text {WALL }}:$ Shear wall length [mm].

$h_{W A L L}:$ Shear wall height [mm].

$t_{\text {DIAPHRAGM }}$ : Diaphragm thickness [mm].

$A_{E X T}$ : Transversal area of shear wall Internal post-studs (Figure 4). 4 packs of $138 \times 35 \mathrm{~mm}$ studs [ $\left.\mathrm{mm}^{2}\right]$.

$A_{I N T}:$ Transversal area of shear wall External post-studs (Figure 4). 4 packs of $138 \times 35 \mathrm{~mm}$ studs [mm²]. 
$e_{O S B}$ : OSB sheathing nominal panel thickness [mm].

$S_{N A L S S}:$ Panel edge nail spacing [mm].

$G_{a}$ : Apparent shear wall shear stiffness from nail slip and panel shear deformation $[\mathrm{kN} / \mathrm{mm}]$.

$\phi_{A T S}:$ Strong-Rod ATS anchor diameter [mm].

\subsection{Linear response-history analysis of the shear wall with and without incorporating the proposed AASD system in its} structure

In order to be able to compare the contribution of the AASD system to the shear wall, an analysis was carried out first without incorporating the displacement dissipation and amplification devices. Subsequently, an analysis considering these devices was carried out to evaluate the level of improvement in the lateral flexibility of these structural systems. For the analysis, an artificial record compatible with the response spectrum of the Chilean NCh2745 (INN 2013) standard was used, assuming Seismic Zone 3 and soil type II. The acceleration record of the ground motion is shown in Figure 28 .

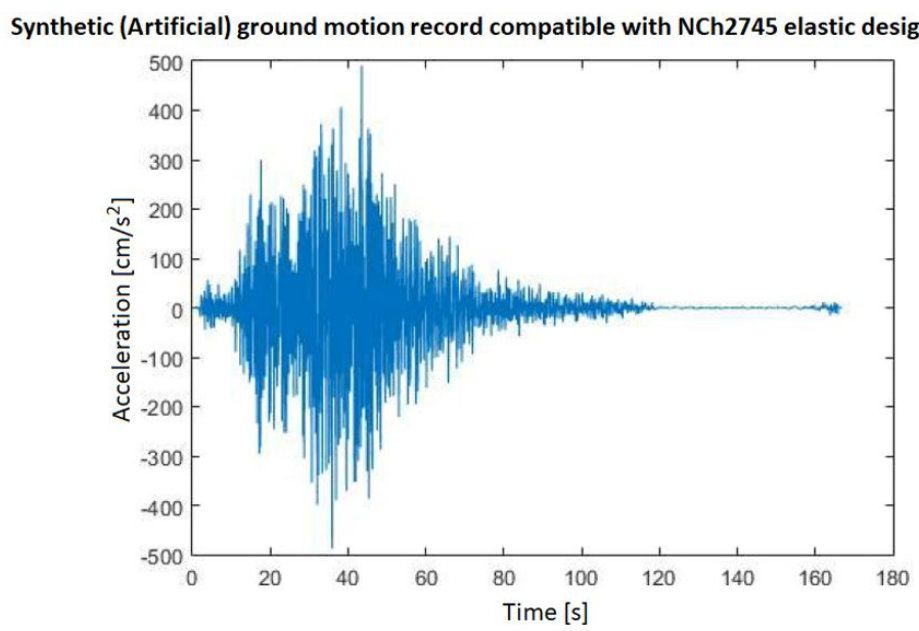

Figure 28. Synthetic ground motion record compatible with NCh2745 code elastic design spectrum (Zone 3 - Soil Type II).

For this analysis, a double ELAS mechanism with its damper was considered (as was described in the previous sections) for each shear wall. To obtain their dynamic response, a Buoc-Wen type numerical model was implemented for the elastoplastic response of the UFP device. Figure 29(a) compares the lateral drift of the MDOF system with and without the AASD mechanism. It is noted that the maximum drift on the third floor decreased by $31.6 \%$.

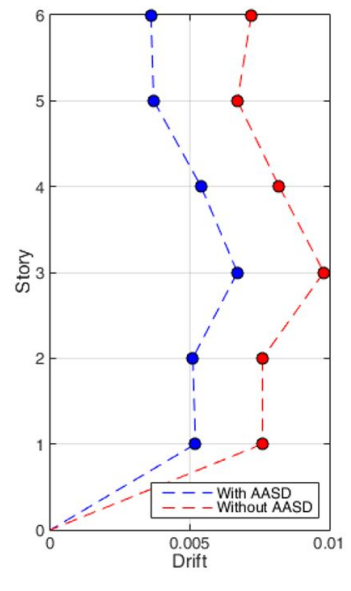

(a)

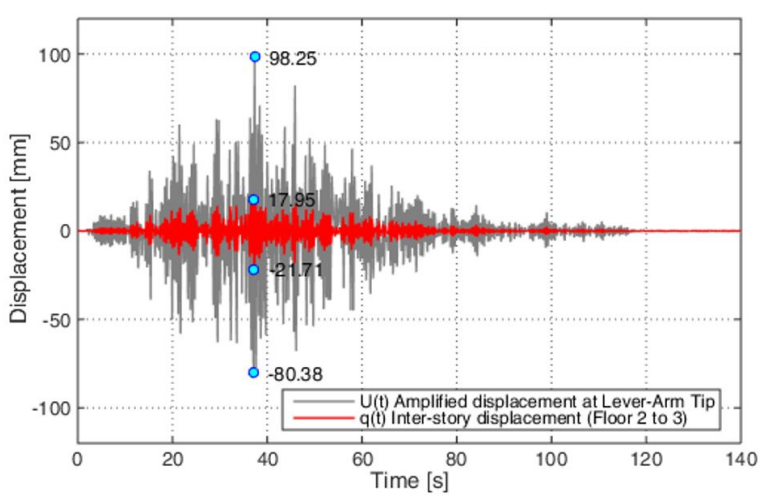

(b)

Figure 29. Lateral drift comparison for the 6-story wood-frame vertical plane with and without the AASD system. 
Figure 29(b) shows the relative displacement between floors 2 and 3, in which the displacement amplification at the end of the ELAS lever for the maximum drift response was $\alpha_{M O D E L}=98.25 / 21.71, \alpha_{M O D E L}=4.53$, which is slightly less than the ideal theoretical amplification, which would be achieved if preventing losses of stiffness at the connections $(\alpha=4.7)$. The energy balance of the system is presented in Figure 30. The model quantified the energy absorbed by the dissipation system as $32 \%$ of the input seismic energy.

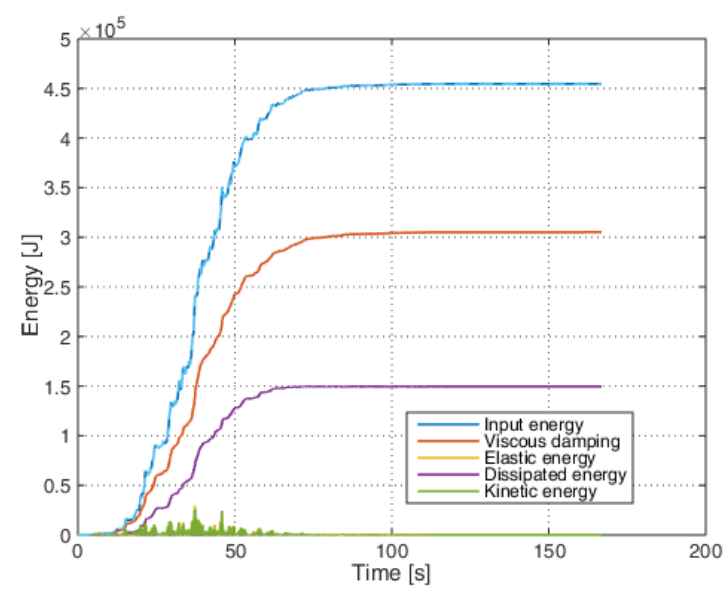

Figure 30. Energy analysis for the 6-story wood-frame vertical plane under investigation.

This analysis shows that using amplification mechanisms combined with energy dissipators allows for improving the lateral performance of the wood-frame structures up to 6 stories. The reduction of the $30 \%$ of inter-story drift can be of paramount importance for mid-rise timber buildings to meet the inter-story drift restraints of building codes.

\section{CONCLUSIONS}

This paper presents the results of an investigation aimed at developing and adapting typical seismic protection devices to wood-frame shear walls. Due to the inherent characteristics of the timbers structures such as geometry, flexibility, weight, strength, and stiffness, traditional seismic protection approaches need to be properly conditioned to provide an improvement in the lateral performance of the system. The main findings of this research are outlined below:

- It is feasible to implement an Amplified Added Stiffening and Damping (AASD) system within wood-frame shear walls. Besides, it was found that it is possible to adapt an Eccentric Lever-Arm System (ELAS) amplification mechanism within the restrictive structure of the timber frame considering its narrow limits dimensions. This integration was achieved without the need for introducing relevant modifications on the timber frame or detriments of the mechanical properties of the shear wall.

- An attempt was made to increase the displacements transmission from the shear wall to the dampers. In this sense, some simple modifications were implemented to stiffen the connections between the ELAS and the timber frame by means of $45^{\circ}$ screws. This resulted in a satisfactory displacement amplification ratio of about 3 and no visible damage to the reinforced connections at the timber frame. However, larger ratios up to 4.7, should be feasible if preventing stiffness losses at the bar diagonals and steel joints of the amplification system. Such losses should be largely mitigated by oversizing the diagonal steel bars and welded joint with the lever-arm.

- When a shear wall with the AASD system is compared with a conventional shear wall, the improvement in the lateral performance is evident. The effective stiffness and strength of the damped shear wall increased by about $13 \%$, while energy dissipation increased by about 32\%, and most importantly, it is expected a $30 \%$ reduction in the interstory drifts.

- The largest improvement of the damping system was seen. However, in terms of resilience, rather than the structural performance of intact shear walls. The unprotected wood-frame shear walls exhibited drops in stiffness, strength, and energy dissipation of about $90 \%$ after two major earthquakes. However, these values drop only about $40 \%$ for the damped shear wall while increasing the damping coefficient ratio. Thus, the degradation of strength and stiffness after major earthquakes have the potential to make conventional timber shear walls ineffective while protected systems still may be bearing reasonable loading and dissipating energy. 
- $\quad$ Future work should focus on increasing the stiffness of critical joints and reducing the losses of displacement transmission from the AM device to dampers. Besides, the development of a simplified methodology to incorporate the AASD system in the seismic design procedure of wood-frame buildings is necessary. In order to maximize design efficiency, such a methodology should represent the ELAS system and dampers as a typical traditional damper. In this way, standard design methodologies can be employed for practitioner engineers when implementing the proposed AASD system in wood-frame structures.

\section{Acknowledgments:}

This research has been funded by CONICYT Chile, FONDECYT PROJECT 11170863, and the APC was also funded by FONDECYT PROJECT 11170863. The authors thank Conicyt for the financial support, as well as the structural lab team of the Laboratory of Structural Engineering of the UC and the team of the Timber Innovation Center CIM-UC.

Author's Contributions: Conceptualization, P Guindos, JL Almazán, J Montaño and R Maury; Investigation, R Maury, P Guindos, JL Almazán and J Montaño; Methodology, R Maury and J Montaño; Formal Analysis, R Maury and JL Almazán; Writing - original draft, J Montaño and R Maury; Visualization, J Montaño; Writing - review \& editing, X Estrella, P Guindos; Funding acquisition, P Guindos; Supervision, J Montaño, JL Almazán, P Guindos.

Editor: Pablo Andrés Muñoz Rojas.

\section{References}

American Wood Council 2015, Special design provisions for wind and seismic, ANSI/AWC SDPWS-2015, Leesburg, VA.

Arizaga, R., and Almazán, J.L., (2019). Estudio experimental de disipadores de energía flexurales UFP con restricción interna e implementación numérica. Tesis Pontificia Universidad Católica de Chile, Santiago, Chile.

Baquero, J.S., Almazán, J.L., Tapia, N., (2016). Amplification system for concentrated and distributed energy dissipation devices. Earthquake Engineering \& Structural Dynamics 45: 935-956.

Berton, S., Bolander, E.B., (2005). Amplification System for Supplemental Damping Devices in Seismic Applications. Journal of Structural Engineering, 131(6), 979-983.

Chung, T.S.K, Lam, E.S.S., (2004). Hydraulic displacement amplification system for energy dissipation. ANCEER Annual Meeting.

Constantinou, M.C., Tsopelas, P., Hammel, W., (1997). Testing and Modeling of an Improved Damper Configuration for Stiff Structural Systems. Technical Report, State University of New York at Buffalo, Buffalo, New York, USA.

Constantinou, M.C., Tsopelas, P., Hammel, W., Sigaher, A.N., (2001). Toggle-braced-damper seismic energy dissipation systems. Journal of Structural Engineering (February) 2001: 105-112.

Dinehart DW, Shenton HW, Elliott TE (1999) The dynamic response of wood-frame shear walls with viscoelastic dampers. Earthq Spectra. 15, 67-86. https ://doi.org/10.1193/1.15860 29.

Dutil DA, Symans MD (2004) Experimental investigation of seismic behavior of light-framed wood shear walls with supplemental energy dissipation. In: 13th World Conference on earthquake engineering. Vancouver, Canada, p 15

Filiatrault A (1990) Analytical predictions of the seismic response of friction damped timber shear walls. Earthq Eng Struct Dyn. 19, 259-273. https ://doi.org/10.1002/eqe.42901 90209.

Higgins C (2001) Hysteretic dampers for wood frame shear walls. In: 2001 Structures congress and exposition, ASCE. D.C., USA.

Hwang, J., Huang, Y., Hung, Y., (2005). Analytical and experimental study of toggle-brace-damper systems. Journal of Structural Engineering (July) 131: 1035-1043.

INN (2013), Análisis y diseño de edificios con aislación sísmica, NCh 2745-2013, Instituto Nacional de Normalización, Santiago, Chile.

Kang, J.D., Hiroshi, T., (2012). Seismic response of steel structures with Seesaw systems using viscoelastic dampers. Earthquake Engineering \& Structural Dynamics 41: 1-16. 
Kang, J.D., Tagawa, H., (2013). Seismic performance of steel structures with seesaw energy dissipation system using fluid viscous dampers. Engineering Structures 56: 431-442.

Kang, J.D., Tagawa, H., (2014). Experimental evaluation of dynamic characteristics of seesaw energy dissipation systems for vibration control structures. Earthquake Engineering \& Structural Dynamics 43: 1889-1895.

Kani, N., Ogura, K., Tsujita, O., Hosozawa, O., Shinozaki, Y., (1992). A design method and development of damping amplifier system for passive response-controlled structure. $10^{\text {th }}$ World Conference of Earthquake Engineering, Balkema, Rotterdam 4165-4170.

Kasai K, Sakata H, Wada A, Miyashita T (2005) Dynamic behavior of a wood frame with shear link passive control mechanism involving K-brace. J Struct Constr Eng 70:51-59

Li Z, Dong H, Wang X, He M (2017) Experimental and numerical investigations into seismic performance of timber-steel hybrid structure with supplemental dampers. Eng Struct. 151, 33-43. https ://doi.org/10.1016/j.engst ruct.2017.08.01.

López-Almansa F, Segués E, Cantalapiedra IR (2015) A new steel framing system for seismic protection of timber platform frame buildings. Implementation with hysteretic energy dissipators. Earthq Eng Struct Dyn 44:1181-1202. https ://doi.org/10.1002/eqe.2507

Shinde, J.K., Symans, M.D., (2010). Integration of seismic protection systems in performance-based seismic design of woodframed structures. Technical Report MCEER-10-0003.

Shinde, J.K., Symans, M.D., Liu, H., Van de Lindt, J.W., (2008). Seismic Performance Assessment of Woodframed Structures with Energy Dissipation Systems. Proceedings of Eighteenth Conference on Analysis and Computation held in Conjunction with ASCE/SEI Structures Congress 2008, Vancouver, Canada, April.

Sigaher, A.N., Constantinou, M.C., (2003). Scissor-jack-damper energy dissipation system. Earthquake Spectra 19(1): $133-158$.

Symans MD, Cofer WF, Du Y, Fridley KJ (2002a) Evaluation of fluid dampers for seismic energy dissipation of woodframe structures. California Institute of Technology and the Consortium of Universities for Research in Earthquake Engineering, Richmond

Symans, M.D. and Constantinou, M.C. (1998). "Passive Fluid Viscous Damping Systems for Seismic Energy Dissipation," J. of Earthquake Technology, 35(4), 185-206.

Symans, M.D., Cofer, W.F., and Fridley, K.J., (2002b). Base Isolation and Supplemental Damping Systems for Seismic Protection of Wood Structures: Literature Review. Earthquake Spectra, 18(3), 549-572.

Ugalde, D., Almazán, J. L., Santa María, H., \& Guindos, P. (2019). Seismic protection technologies for timber structures: a review. European journal of wood and wood products, 77(2), 173-194. 